\title{
Large-eddy simulation and experimental study of heat transfer, nitric oxide emissions and combustion instability in a swirled turbulent high-pressure burner
}

\author{
By PATRICK SCHMITT ${ }^{1}$, T. POINSOT ${ }^{2}$, B. SCHUERMANS ${ }^{3}$ \\ AND K. P. GEIGLE \\ ${ }^{1}$ CERFACS, 42 Avenue Gaspard Coriolis, 31057 Toulouse cedex 1, France \\ ${ }^{2}$ IMFT, Allée du Professeur Camille Soula, 31400 Toulouse, France \\ ${ }^{3}$ ALSTOM Power Ltd., Pavillion 3.2, 5401 Baden, Switzerland \\ ${ }^{4}$ DLR, Pfaffenwaldring 38-40, 70569 Stuttgart, Germany
}

(Received 14 December 2005 and in revised form 19 May 2006)

\begin{abstract}
Nitric oxide formation in gas turbine combustion depends on four key factors: flame stabilization, heat transfer, fuel-air mixing and combustion instability. The design of modern gas turbine burners requires delicate compromises between fuel efficiency, emissions of oxides of nitrogen $\left(\mathrm{NO}_{X}\right)$ and combustion stability. Burner designs allowing substantial $\mathrm{NO}_{X}$ reduction are often prone to combustion oscillations. These oscillations also change the $\mathrm{NO}_{X}$ fields. Being able to predict not only the main species field in a burner but also the pollutant and the oscillation levels is now a major challenge for combustion modelling. This must include a realistic treatment of unsteady acoustic phenomena (which create instabilities) and also of heat transfer mechanisms (convection and radiation) which control $\mathrm{NO}_{X}$ generation.

In this work, large-eddy simulation (LES) is applied to a realistic gas turbine combustion chamber configuration where pure methane is injected through multiple holes in a cone-shaped burner. In addition to a non-reactive simulation, this article presents three reactive simulations and compares them to experimental results. The first reactive simulation neglects effects of cooling air on flame stabilization and heat losses by radiation and convection. The second reactive simulation shows how cooling air and heat transfer affect nitric oxide emissions. Finally, the third reactive simulation shows the effects of combustion instability on nitric oxide emissions. Additionally, the combustion instability is analysed in detail, including the evaluation of the terms in the acoustic energy equation and the identification of the mechanism driving the oscillation.
\end{abstract}

Results confirm that LES of gas turbine combustion requires not only an accurate chemical scheme and realistic heat transfer models but also a proper description of the acoustics in order to predict nitric oxide emissions and pressure oscillation levels simultaneously.

\section{Introduction}

Large-eddy simulations (LES) of reactive flows are becoming a standard approach for designing and understanding gas turbine combustion chambers (Angelberger, 


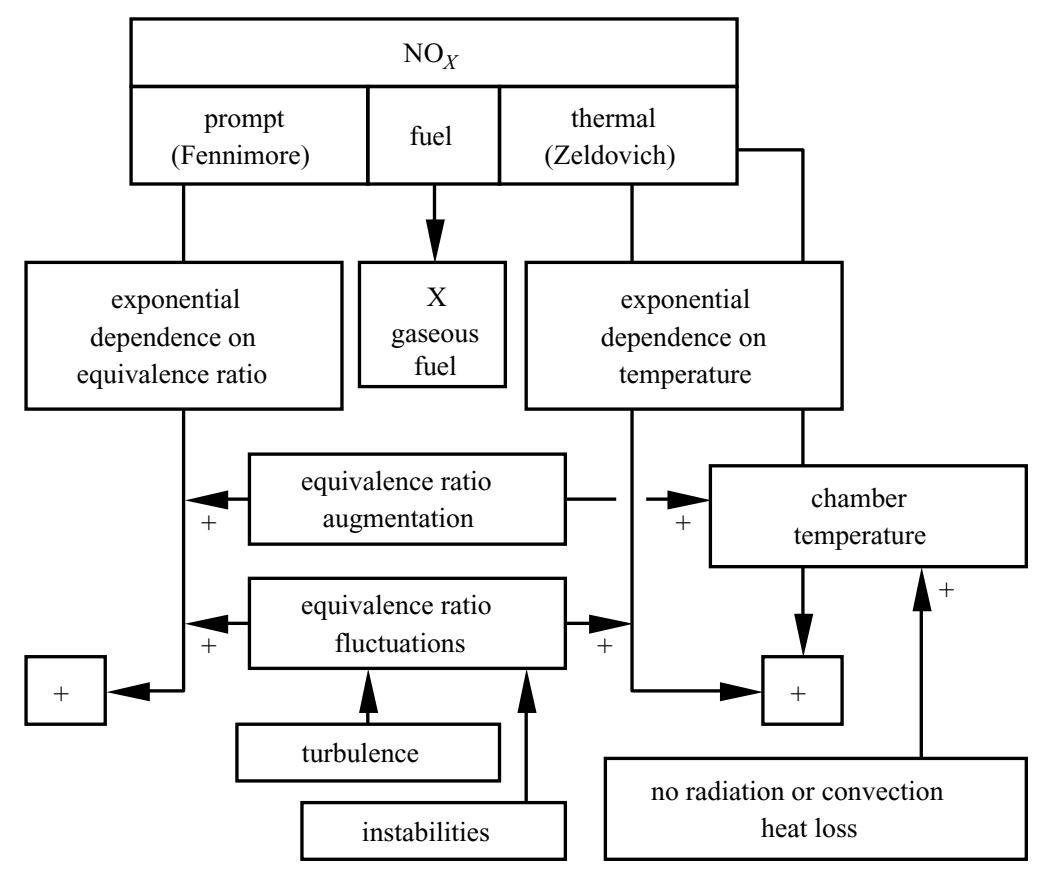

FIGURE 1. Diagram of factors influencing $\mathrm{NO}_{X}$ concentration in gas turbine combustion.

Veynante \& Egolfopoulos 2000; Moin, Pierce \& Pitsch 2000; Branley \& Jones 2001; Selle et al. 2004a; Janicka \& Sadiki 2005). One central issue today is the emission characteristics of the combustion process: the concentration of oxides of nitrogen $\left(\mathrm{NO}_{X}\right)$ for example in the exhaust gases is strongly limited by regulations (Lefebvre 1998). To be able to predict these emissions, all physical phenomena influencing their formation (figure 1) must be taken into account. It is convenient to divide them in three groups: thermal $\mathrm{NO}_{X}$, fuel $\mathrm{NO}_{X}$ and prompt $\mathrm{NO}_{X}$ (Glarborg, Miller \& Kee 1986; Miller \& Bowman 1989; Nicol et al. 1992):

Thermal $\mathrm{NO}_{X}$ (Zeldovich mechanism) is formed everywhere where oxygen and nitrogen are present and temperatures are sufficiently high. It depends exponentially on temperature which makes it very sensitive to turbulent and acoustic fluctuations.

Fuel $\mathrm{NO}_{X}$ has its origin in nitrogen, which is bound to the hydrocarbon fuel. As only pure methane combustion is considered in this work, this mechanism is not important here.

Prompt $\mathrm{NO}_{X}$ (Fennimore mechanism) is formed in the flame via the intermediate of hydrocarbon radicals. It is convenient to group this mechanism with the nitrous oxide mechanism (an additional reaction path) as both are active close to the flame front and have an exponential dependence on equivalence ratio.

To predict how these mechanisms occur in turbulent flames, it is necessary not only to have a proper description of chemical kinetics but also of the mean fields of temperature and equivalence ratio as well as of the fluctuating fields of temperature and equivalence ratio (figure 1). These fluctuations can be due to turbulence but also to acoustic effects: in most gas turbines, $\mathrm{NO}_{X}$ emissions change when the pressure oscillation levels vary. Capturing all mechanisms listed in figure 1 is therefore the objective of an LES. This is obviously a daunting task since all these phenomena 
(chemistry, radiation, convective heat transfer, instabilities) are still open issues when studied individually. Coupling all of them in an LES requires drastic simplifications:

(i) chemistry is modelled here using reduced schemes $(\$ 2.2)$;

(ii) flame/turbulence interaction is modelled by the artificially thickened flame model $(\S 2.3)$;

(iii) a law of the wall approach is developed for convective heat transfer at walls and a Stefan-Boltzmann model is used to evaluate radiation effects $(\$ 2.4)$;

(iv) acoustic effects are accounted for using a compressible formulation and boundary conditions which allow control of impedances and oscillation levels $(\$ 2.5)$.

Section 3 presents the configuration of the burner studied and its thermal and acoustic properties. Section 4 describes the experimental setup and the diagnostics techniques. Section 5 compares the results of the non-reactive simulation in terms of velocities and mixing to water channel experiments. Section 6 compares flame position and shape, velocities, emissions and instability characteristics of the reactive simulations to experiment. An acoustic analysis of the combustion instability is also conducted.

\section{Modelling}

\subsection{Numerical solver}

The LES solver is a fully unstructured compressible finite-volume/-element code, including species transport and variable heat capacities (Moureau et al. 2005). Centred spatial schemes and explicit time-advancement are used to control numerical dissipation and capture acoustics (Colin \& Rudgyard 2000). Smagorinsky's LES model (Smagorinsky et al. 1963) and the Lax-Wendroff scheme are used. Characteristic boundary conditions (Poinsot \& Lele 1992; Baum, Thevenin \& Poinsot 1994) are used at all boundaries.

\subsection{Chemistry modelling}

The chemistry used for all simulations corresponds to a 3-step reduced mechanism for methane/air combustion:

$$
\begin{gathered}
\mathrm{CH}_{4}+1.5 \mathrm{O}_{2} \rightarrow \mathrm{CO}+2 \mathrm{H}_{2} \mathrm{O} \\
\mathrm{CO}+0.5 \mathrm{O}_{2} \leftrightarrow \mathrm{CO}_{2} \\
\mathrm{O}_{2}+\mathrm{N}_{2} \rightarrow 2 \mathrm{NO}
\end{gathered}
$$

The reaction rates for equations (2.1a) and (2.1b) are of Arrhenius type and were obtained using a genetic optimizer (Martin 2004). As the gas turbine burner considered operates in the lean partially premixed regime, the Arrhenius coefficients were optimized to match premixed laminar flame speeds and temperatures of the 3-step reduced mechanism to the Gri-Mech 3.0 (Smith et al. 1999) from lean (equivalence ratio $\phi=0.4)$ to moderately rich $(\phi=1.1)$ premixed regimes. The Arrhenius coefficients for the reduced mechanism are detailed in the Appendix. The reaction rate for equation $(2.1 c)$ is the sum of two rates, one for thermal NO (only dependent on temperature) and one for prompt $\mathrm{NO}$ (depending on $\mathrm{CH}_{4}$ and $\mathrm{H}_{2} \mathrm{O}$ concentrations). Most $\mathrm{NO}$ reacts to become $\mathrm{NO}_{2}$ after combustion. However, close to the combustion area, NO is dominant. Therefore, it is sufficient to limit the chemical scheme to NO (Lefebvre 1998).

Figure 2 presents laminar flame speeds, thicknesses and adiabatic flame temperatures obtained with the Gri-Mech 3.0 and the optimized reduced 3-step mechanism 


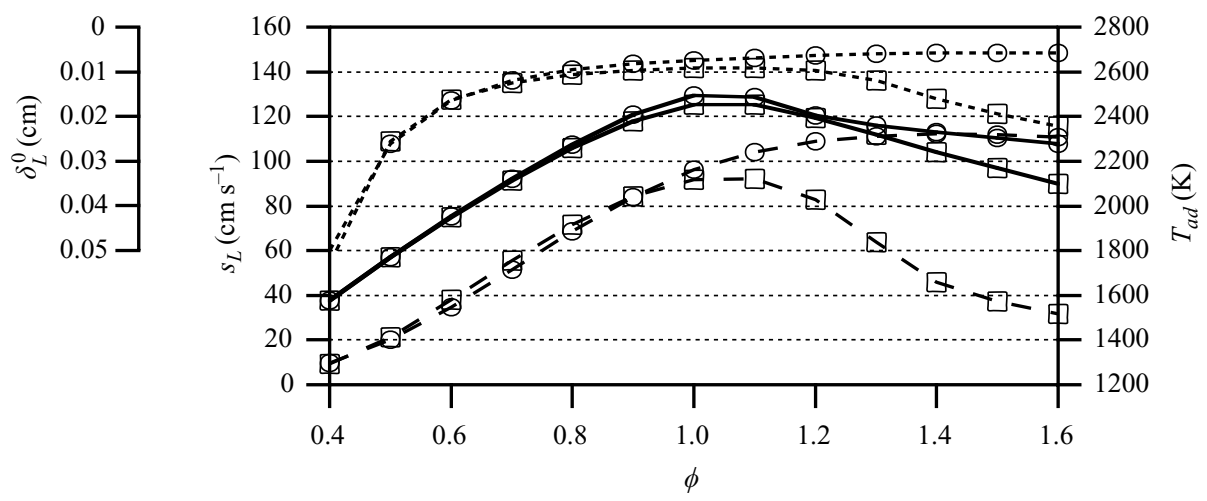

FIgURE 2. Adiabatic flame temperatures $\left(T_{a d},-\right)$, laminar flame speeds $\left(s_{L},---\right)$ and thermal flame thickness $\left(\delta_{L}^{0}\right.$, - - - ) of the GRI-Mech 3.0 (squares) compared to the 3S_CH4_PS1-scheme (circles).
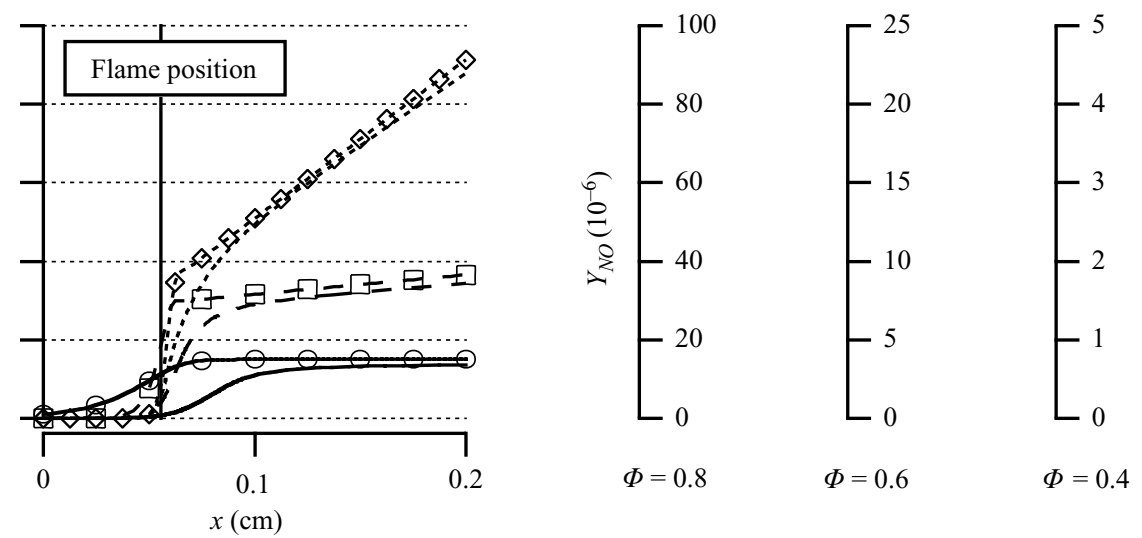

FIGURE 3. NO mass fraction from the 3S_CH4_PS1-scheme (symbols) and from the GRI-Mech 3.0 (no symbols) for $\phi=0.4(-), 0.6(---)$ and $0.8(---)$.

(called 3S_CH4_PS1) for laminar one-dimensional premixed flames. Both results were obtained with PREMIX (Kee et al. 1998) at $p=0.5 \mathrm{MPa}$ and $T_{i n}=660 \mathrm{~K}$ and match well for lean equivalence ratios. Figure 3 displays NO mass fraction profiles for laminar premixed flames for fuel equivalence ratios of $0.4,0.6$ and 0.8 . Note the strong thermal NO production after the flame for $\phi=0.8$. Again, the Gri-Mech 3.0 and the reduced 3-step mechanism match well.

This 3-step scheme (equations $(2.1 a)$ to $(2.1 c)$ ) performs well for the present conditions, but would not work with identical coefficients for other cases (different pressures or inlet temperatures). The strength of this approach (initially used for DNS by Bédat, Egolfopoulos \& Poinsot 1999) is that it makes LES of one regime possible. Its drawback is that the fitting process must be repeated for every regime.

\subsection{Flame/turbulence interaction model}

Multiple models are being developed for perfectly premixed flames (Chakravarthy \& Menon 2000; Duchamp de Lageneste \& Pitsch 2000; Peters 2000; Janicka \& Sadiki 2005; Poinsot \& Veynante 2005). Handling situations where partially premixed flames may exist together with mixing and/or quenched zones is still a research issue. In the present study, the artificially thickened flame model (TFLES) is used (Colin et al. 
2000). Its goal is to thicken the flame front until it can be resolved on a typical LES mesh. This procedure avoids making assumptions on the flame topology and allows the computation of partially premixed flames for example. From asymptotic analysis of laminar premixed flames simple expressions for the laminar flame speed $\left(s_{L}\right)$ and thickness $(\delta)$ follow:

$$
s_{L} \propto \sqrt{\lambda A}, \quad \delta \propto \frac{\lambda}{s_{L}}=\sqrt{\frac{\lambda}{A}},
$$

where $\lambda$ is the thermal conductivity and $A$ the pre-exponential constant of a global reaction. If the thermal conductivity is increased by a factor $F$ while the preexponential constant is decreased by $F$, the flame thickness $\delta$ is multiplied by $F$ while the flame speed $s_{L}$ is maintained (Butler \& O'Rourke 1977).

In all LES formulations, the interaction between turbulence and chemistry at the subgrid level has to be modelled. This is accomplished here by an 'efficiency function' $E$ that takes into account the effects of thickening and residual turbulence on the turbulent flame speed (Colin et al. 2000). Following the multi-fractal model of the ITNFS approach by Meneveau \& Poinsot (1991), the ability of different turbulence length scales to wrinkle the flame is measured in DNS of flame/vortex interactions (Poinsot, Veynante \& Candel 1991) and integrated in the efficiency function $E$.

Multiplying the thermal diffusivity and the pre-exponential constant by the efficiency function $E$ still keeps the flame thickness constant but accelerates the flame by a factor $E$ so that the subgrid turbulent flame speed $s_{T}$ and the LES flame thickness $\delta_{T}$ become

$$
s_{T}=E s_{L}, \quad \delta_{T}=F \delta_{L}^{0} .
$$

The TFLES model is well-adapted to large-scale combustion instabilities because reaction rates are explicitly resolved (using Arrhenius rates) so that the effects of pressure waves for example are captured. Large-scale vortices (which are crucial in many unstable combustors) are also captured well by the TFLES model. The scales which are 'lost' by the model are the small flame wrinkling scales which play a secondary role for stability and can be handled through the efficiency function.

The TFLES model has been applied successfully in many configurations (premixed and partially premixed) and more detailed descriptions may be found in Angelberger et al. (2000), Colin et al. (2000), Selle et al. (2004a) or Martin et al. (2004).

\subsection{Thermal modelling}

Owing to the possible strong contribution of thermal NO to the NO concentration, it is important to predict the temperature field correctly. Even if combustion is properly described, the exact temperature field can only be predicted if two other phenomena are taken into account: convective heat exchange and radiative heat exchange. As a compromise between computational cost and accuracy, the following models are chosen:

(i) Convective heat transfer is modelled by thermal wall-functions. The logarithmic law of the wall for temperature and velocity is applied locally and instantaneously at the solid boundaries (Grötzbach 1987). Section 2.4.1 describes these wall models and presents their validation in an LES of channel flow with heat transfer.

(ii) Radiative heat transfer is modelled by a Stefan-Boltzmann law which depends on local gas composition. Re-absorption and inhomogeneous wall temperatures are neglected (Barlow et al. 2001). Section 2.4.2 shows how this simple model is coupled with the LES. 


\subsubsection{Convective heat transfer modelling}

The description of wall mechanisms is the weak point of LES (Sagaut 2000; Cabot \& Moin 2000): in most reactive LES in complex geometries, the resolution of the boundary layer region is computationally out of reach. Different strategies to model the turbulent boundary layer are reviewed in Piomelli \& Balaras (2002). Here, the computationally least expensive approach is chosen: applying the logarithmic law to velocity and temperature to predict friction and wall heat flux (Schumann 1975; Grötzbach 1987). In contrast to Grötzbach (1987), who used mean temperature and velocity values, instantaneous values were used in this study. This assumes that the computational cells at the wall are sufficiently large to contain several typical structures of near-wall turbulence.

In order to apply a wall-function boundary condition, the classical no-slip condition at solid walls is abandoned and only the wall-normal velocity is set to zero (in the case of a cell-vertex type solver). Additionally, the wall shear stress and heat flux are imposed. The friction velocity $u_{\tau}$ is obtained by iteratively solving the logarithmic law of the wall:

$$
\frac{u}{u_{\tau}}=\kappa^{-1} \ln \left(A \frac{y u_{\tau}}{v}\right)
$$

where $u$ is the velocity at the first interior grid node, $\kappa=0.41$ the von Kármán constant, $A=9.2$ an integration constant, $y$ the distance from the first interior grid point to the wall, and $v$ the kinematic viscosity. The wall shear stress $\tau_{\text {wall }}$ is then calculated as $\rho u_{\tau}^{2}$, with $\rho$ being the local density.

As the logarithmic law of the wall was derived for the mean flow and considering that most near-wall turbulence is not resolved, the residual stress model should degenerate near the wall to a mixing-length-type model. This is the case for Smagorinsky's model (Smagorinsky, Manabe \& Holloway 1963), which is well-suited to this kind of simulation. Cabot \& Moin (2000) showed that in the near-wall region, the classic Smagorinsky model with wall functions gives better results than the dynamic model with wall functions.

From the logarithmic law for temperature, the wall heat flux $q_{\text {wall }}$ is calculated using

$$
\frac{\rho_{\text {wall }} u_{\tau} C_{p}\left(T_{\text {wall }}-T\right)}{q_{\text {wall }}}=\kappa^{-1} \ln \left(B \frac{y u_{\tau}}{\nu}\right)
$$

where $C_{p}$ is the heat capacity at constant pressure, $T_{\text {wall }}$ the wall temperature, $T$ the temperature at the first interior grid point, and $B=2.96$ an integration constant. For flows with Prandtl numbers $(P r)$ very different from unity, more sophisticated formulations for the temperature law may be used (Launder \& Spalding 1974).

This approach only gives good results for attached flows (Piomelli \& Balaras 2002). This should not cause major errors in this case, since the heat transfer is mainly important in regions where the flow is locally attached (such as downstream in the chamber or on the front plate).

Validation of the convective heat transfer was done by performing an LES of a periodic channel flow with heat transfer (figure 4) at low Mach number $(M a=0.1)$. The flow is sustained by the appropriate momentum source term (Deardorff 1970). Quasi-isothermal simulations (with only viscous heating) as well as simulations involving temperature gradients (using a volume heat source term) comparable to those encountered in real combustion chambers were carried out. Figure 5(a) shows the non-dimensional mean velocity profile of the quasi-isothermal simulation at $R e_{\tau}=\delta u_{\tau} / v=1500$, where $\delta$ is half the channel height. It is compared to the 


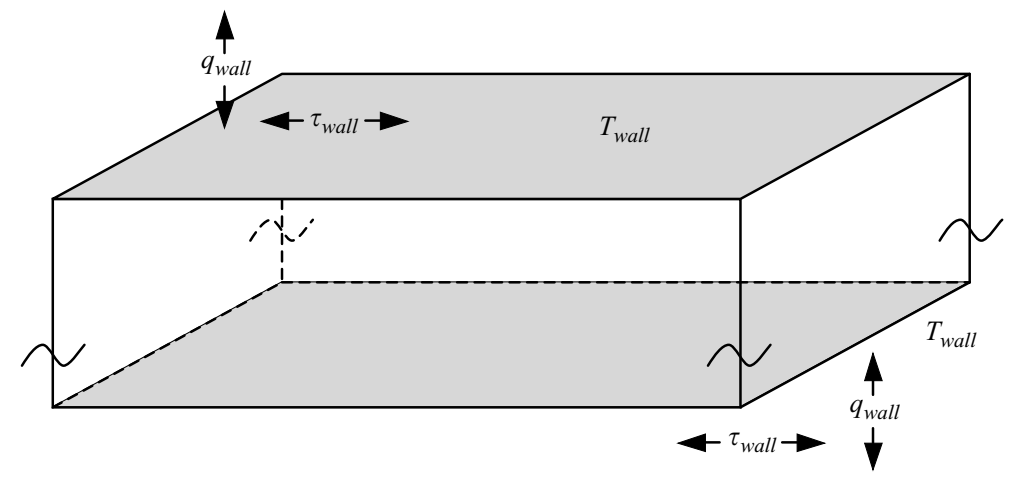

FIGURE 4. Schematic of a periodic channel. The upper and lower boundaries are walls, all other boundaries are pairwise periodic.
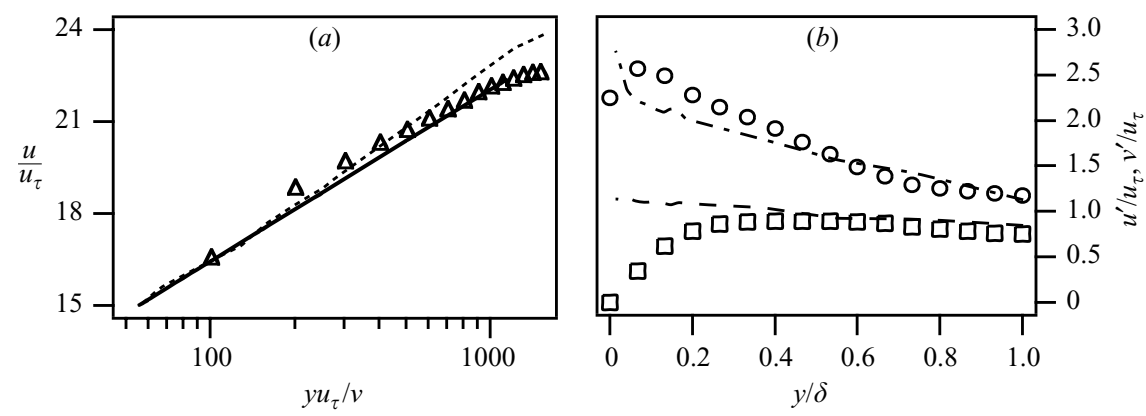

FiguRE 5. (a) Mean axial (triangles) and (b) fluctuating velocity profiles (circles, axial; squares, wall-normal) from the channel-flow simulations compared to the logarithmic law ( - ) and experiment (- - -, mean axial; - - -, axial r.m.s.; - - , wall-normal r.m.s).

logarithmic law of the wall and measurements of Wei \& Willmarth (1989). The first grid point is at a reduced distance $y u_{\tau} / \nu \approx 100$ from the wall. Predictions inside the channel are good, but this approach shows difficulties in correctly predicting the velocity profile in the region near the wall where the simulation changes from a more RANS-type flow to a true LES. Figure $5(b)$ shows axial and wall-normal velocity fluctuations. The simulation shows good behaviour far from the wall but near the wall, wall-normal turbulence is under-predicted.

In order to verify the behaviour of the wall-function for high temperature gradients, a simulation which includes a volume heat source term was carried out. For nonisothermal boundary flows, an additional number, the non-isothermicity parameter $\xi$, must be introduced (Poinsot \& Veynante 2005):

$$
\xi=-\frac{q_{\text {wall }}}{\rho_{\text {wall }} u_{\tau} C_{p} T_{\text {wall }}} \text {. }
$$

In real combustion systems, $\xi$ can reach values greater than 0.5 . The quasi-isothermal simulation (figure 5) has a non-isothermicity parameter of $\xi=10^{-4}$, that with volumetric heat source has $\xi=0.27$. In order to compare the simulations with experimental correlations, the Nusselt number is calculated:

$$
N u=2 \delta \frac{q_{\text {wall }}}{T_{\text {mean }}-T_{\text {wall }}} \frac{P r}{\rho \nu C_{p}} .
$$




$\begin{array}{ccccc}R e & \xi & \begin{array}{c}N u \text { from } \\ \text { correlation }\end{array} & \begin{array}{c}N u \text { from } \\ \text { simulation }\end{array} & \text { Difference } \\ 65888 & 10^{-4} & 149.7 & 156.1 & +4.3 \% \\ 82301 & 0.27 & 176.4 & 192.9 & +9.3 \%\end{array}$

TABLE 1. Nusselt numbers from correlation and simulation for the quasi-isothermal case and the case with volume heat source term.

Nusselt numbers for both simulations are presented in table 1 and compared to the correlation given by Taine \& Petit (1995):

$$
N u=0.023 \operatorname{Re}^{4 / 5} \operatorname{Pr}^{1 / 3}
$$

where $R e$ is the Reynolds number, calculated with the bulk velocity and the channel height. For $\xi=10^{-4}$ an error of $4.3 \%$ is found and for $\xi=0.27$ the error grows to $9.3 \%$. Keeping in mind the level of simplification for these simulations, these errors are acceptable and confirm that this simple wall treatment is a reasonable model in the present framework.

\subsubsection{Radiative heat transfer modelling}

Radiative heat transfer modelling of gases (excluding particles) normally takes into account emitted radiation and re-absorption. The degree of importance of reabsorption is usually determined by the optical thickness $\tau=X / L_{P}$ of the radiating gas, where $X$ is a characteristic dimension of the enclosure and $L_{P}$ the burned-gas Planck mean absorption length (Ju, Masuya \& Ronney 1998). For the configuration considered, $\tau$ is of the order of 0.5 , so that re-absorption is not the dominant process and can be neglected. Furthermore, virtually no preheating of the fresh gases due to absorption occurs since it is assumed that they consist of undiluted air with small amounts of methane (lean conditions).

Assuming that the gases are optically thin and that the cold surroundings (usually the chamber walls) have a constant temperature $T_{s}$, the radiative heat loss per unit volume $Q_{r}$ can be calculated (Barlow et al. 2001):

$$
Q_{r}=4 \sigma\left(T^{4}-T_{s}^{4}\right) \sum_{i}\left(p_{i} a_{p, i}\right)
$$

where $\sigma=5.669 \times 10^{-8} \mathrm{~W} \mathrm{~m}^{-2} \mathrm{~K}^{-4}$ is the Stefan-Boltzmann constant, $T$ is the local gas temperature, $p_{i}$ is the partial pressure of species $i$, and $a_{p, i}$ is the Planck mean absorption coefficient for species $i$. This model requires the partial pressures of the species involved, which are directly obtained from the LES data. For combustion of pure air and methane only $\mathrm{H}_{2} \mathrm{O}$ and $\mathrm{CO}_{2}$ in the burnt gases contribute significantly to radiation as they have high partial pressures and Planck mean absorption coefficients. Therefore, only those two species are included for the evaluation of the radiative heat loss $Q_{r}$. The Planck mean absorption coefficients are calculated from curve-fits provided by Gore et al. (1999), which match the values given by the the RADCAL programme (Grosshandler 1993).

Note that including more detailed radiation predictions by taking into account spatially varying wall temperatures and/or absorption would necessitate much more expensive implementations, such as for example the one presented by David (2004), that make a complete LES impossible to achieve. 


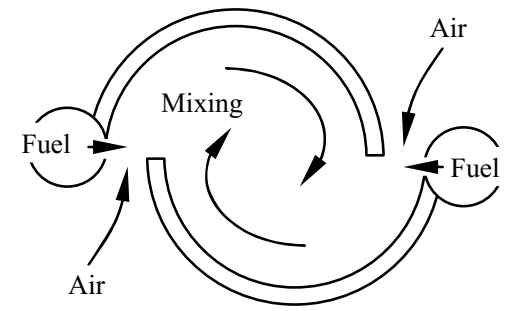

FIGURE 6. Cut perpendicular to the $x$-axis through the burner.

\subsection{Acoustic modelling}

In order to capture combustion instabilities, not only a fully compressible formulation, but also appropriate boundary conditions are needed. The characteristic boundary conditions (Poinsot \& Lele 1992; Baum, Thevenin \& Poinsot 1994) allow construction of an outlet boundary condition which avoids pressure drifts while imposing the amplitude of the reflection coefficient $R_{K}$ :

$$
\mathscr{L}_{1}=K\left(P-P_{\text {target }}\right)+R_{K} \mathscr{L}_{5}
$$

where $\mathscr{L}_{5}$ is the outgoing acoustic wave and $\mathscr{L}_{1}$ the incoming acoustic wave. $P$ is the local pressure and $P_{\text {target }}$ the pressure at infinity towards which the user wants the flow to converge. $K$ is the pressure relaxation value of the NSCBC condition (Poinsot \& Veynante 2005). Carrying out the same analysis as in Selle, Nicoud \& Poinsot (2004b), an expression for the outlet reflection coefficient $R$ is obtained:

$$
R=\frac{\mathscr{L}_{1}}{\mathscr{L}_{5}}=-R_{K}+\frac{R_{K}-1}{1-i(2 \omega / K)}
$$

where $\omega$ is the angular frequency of the outgoing wave. For angular frequencies lower than $\omega=K / 2$ this boundary condition is fully reflecting (thereby imposing the pressure) (Selle et al. 2004b). For angular frequencies higher than $K / 2$, this formulation imposes a reflection coefficient of $|R| \approx R_{K}$ with a phase of $-\pi$. The right choice of $R_{K}$ allows the evacuation of a defined amount of acoustic energy. This is essential for obtaining simulations comparable to reality.

\section{Burner geometry and setup}

\subsection{General description}

The burner used for this study is a scaled industrial configuration (Doebbeling et al. 1999). It consists of two half-cones (the cone angle is $11^{\circ}$ ) shifted with respect to each other in order to create a swirling flow. This principle is illustrated in figure 6 where a perpendicular cut through the shifted half-cones (called burner from now on) is shown. Air enters through the slots formed by the half-cones, and fuel through holes which inject perpendicularly to the slots. They mix in the swirl flow which forms inside the burner.

Figure 7 provides a schematic view of the burner and the combustion chamber. Pre-heated air from the plenum and fuel from 16 holes at the burner entry mix rapidly inside the burner (left side of the figure). As the flow exits to the combustion chamber (right side of the figure), a central recirculation zone is formed by the breakdown of the swirling flow. The hot recirculating gases stabilize the lean partially premixed flame close to the burner without the flame touching the burner. The combustion products exit through a chimney on the right (not shown in figure 7). 


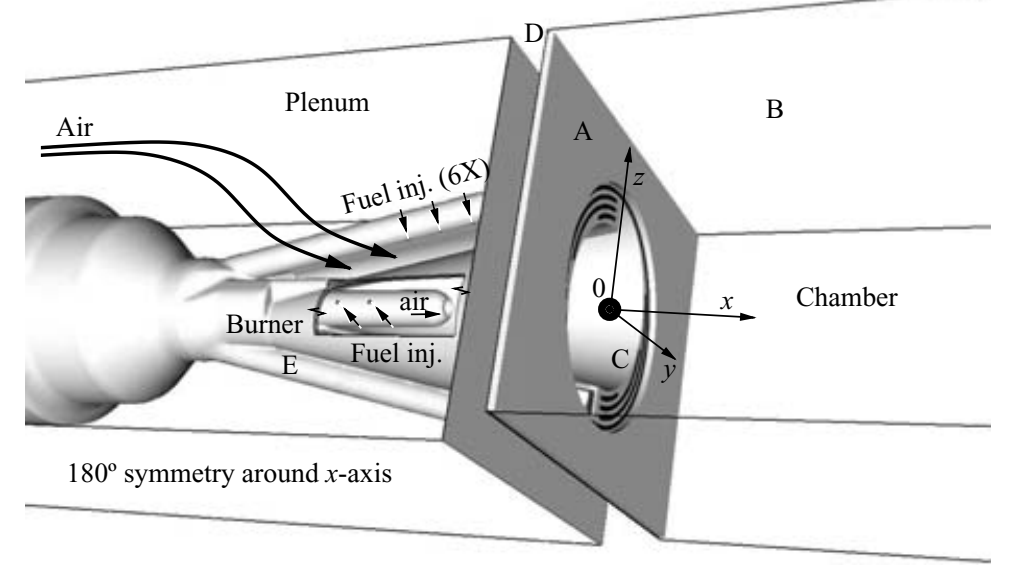

FIGURE 7. Schematic of the burner and chamber geometry studied. (A) cooled front plate; (B) thin steel wall; (C) air cooling at burner front; (D) film cooling at chamber edge; (E) burner.

$\begin{array}{lccccc}\text { Boundary } & \text { Mass flux } & \text { Pressure } & \text { Temperature } & \text { Species } & K \\ \text { Air inflow } & 0.2905 \mathrm{~kg} \mathrm{~s}^{-1} & - & 673 \mathrm{~K} & \text { air } & 500 \mathrm{~s}^{-1} \\ \text { Fuel } & 0.0092 \mathrm{~kg} \mathrm{~s}^{-1} & - & 293 \mathrm{~K} & \mathrm{CH}_{4} & 10^{4} \mathrm{~s}^{-1} \\ \text { Outlet } & - & 0.5 \mathrm{MPa} & - & - & 150 \mathrm{~s}^{-1} \\ \text { Walls (A,B and E in figure 7) } & & \text { Adiabatic wall-function }\end{array}$

TABLE 2. Boundary conditions for case 1.

The definition of the $x$-, $y$ - and $z$-directions is also seen in figure 7. The origin is located at the burner exit (diameter $D=7 \mathrm{~cm}$ ). The two slots formed by the half-cones lie in the $y=0$ plane. The plenum has a square cross-section $(12 \mathrm{~cm} \times 12 \mathrm{~cm})$ while the chamber is rectangular (width in $y$-direction: $14 \mathrm{~cm}$, height in $z$-direction: $11 \mathrm{~cm}$ ).

The computational mesh for the simulations consists of approximately 3 million tetrahedral cells. The diameter of the fuel injection holes was meshed with 5 cells. The mesh size in the mixing zone is typically equal to the diameter of the injection holes, whereas in the flame zone, it is twice the diameter of the injection holes. 150 hours of CPU time on a HP Alphaserver EV68 $1.25 \mathrm{Ghz}$ is needed to advance the simulation by $1 \mathrm{~ms}$.

\subsection{Thermal properties}

The combustion chamber is used as a preheating device for the combustion air which flows around it and then enters the plenum. The main part of the air entering the plenum flows through the burner. Additionally, pre-heated air from the plenum is drawn through small holes at the burner front ( $\mathrm{C}$ in figure 7$)$ to protect the burner from the flame. At the edges between front plate (A) and chamber walls (B), pre-heated air from the plenum is also added to protect the chamber walls (film cooling; D).

All simulations include the plenum, burner and combustion chamber. The flow around the combustion chamber is not simulated. The temperature of the air entering the plenum is specified at the measured value of $673 \mathrm{~K}$. The simulation called case 1 neglects all other heat transfer processes and air cooling of the configuration. The corresponding boundary conditions are summarized in table 2 . The specified mass 


\begin{tabular}{lccccc}
\hline Boundary & Mass flux & Pressure & Temperature & Species & $K$ \\
Air inflow & $0.2651 \mathrm{~kg} \mathrm{~s}^{-1}$ & - & $673 \mathrm{~K}$ & air & $500 \mathrm{~s}^{-1}$ \\
Fuel & $0.0092 \mathrm{~kg} \mathrm{~s}^{-1}$ & - & $293 \mathrm{~K}$ & $\mathrm{CH}_{4}$ & $10^{4} \mathrm{~s}^{-1}$ \\
Cooling front & $0.0164 \mathrm{~kg} \mathrm{~s}^{-1}$ & - & $673 \mathrm{~K}$ & air & $10^{7} \mathrm{~s}^{-1}$ \\
Cooling film & $0.0090 \mathrm{~kg} \mathrm{~s}^{-1}$ & - & $453 \mathrm{~K}$ & air & $10^{7} \mathrm{~s}^{-1}$ \\
Outlet & - & $0.5 \mathrm{MPa}$ & - & - & $150 \mathrm{~s}^{-1}$ \\
Burner walls (E in figure 7) & Wall-function with imposed temperature at $673 \mathrm{~K}$ \\
Frontplate (A in figure 7) & Wall-function with imposed temperature at 700 K \\
Chamber walls (B in figure 7) & \multicolumn{2}{c}{ Wall-function with imposed temperature at 1000 K } \\
TABLE 3. Boundary conditions for cases 2 and 3 and the non-reactive simulation. \\
\hline
\end{tabular}

fluxes result in an adiabatic mean flame temperature of $1850 \mathrm{~K}$. The pressure for all cases is $0.5 \mathrm{MPa}$ (as in the experiment).

While simulation case 1 corresponds essentially to adiabatic conditions for the combustion chamber, cases 2 and 3 incorporate effects of air cooling at the burner front ( $\mathrm{C}$ in figure 7), film cooling ( $\mathrm{D}$ in figure 7 ) and heat losses at chamber walls by convection and radiation.

The chamber wall temperature (B in figure 7) was measured as approximately $1000 \mathrm{~K}$ and this value is used for the boundary condition in LES. The cooled front plate (A in figure 7) has approximately the temperature of the fresh gases $(700 \mathrm{~K})$. Values of mass fluxes, temperatures and compositions are summarized in table 3. Note that the cooling air is diverted from the global air inflow to obtain the same adiabatic flame temperature as for case 1. Additionally, cases 2 and 3 include radiation modelling with the temperature of the surroundings $T_{S}$ (in equation (2.9)) set to $1000 \mathrm{~K}$.

\subsection{Acoustic properties}

Specifying boundary conditions in the LES which match the DLR experiment (see §4) is quite difficult: the plenum inlet and chamber outlet geometries of the experiment are complicated and must be replaced in the LES by simpler shapes, which should ensure a very similar flow and similar acoustics. The experimental chamber and its simplification for LES are compared in figures $8(a)$ and $8(b)$. This simplification requires no significant approximation for the inlet: indeed, the plenum inlet in the experiment consists of a relatively large vessel with a sieve around the burner and is therefore essentially non-reflecting. For the LES it is replaced by a simple square duct, with a non-reflecting inlet (Poinsot \& Lele 1992).

The outlet is more difficult to model: the experimental outlet geometry consists of a sudden contraction, an expansion into a long chimney, another contraction with following expansion and cooling by water jets. None of these components can be included in the LES and the whole outlet geometry is replaced by extending the chamber and terminating it with a partially reflecting boundary condition $(\S 2.5)$. This allows the imposition of various reflection coefficients for the chamber outlet section, ranging from completely non-reflecting to fully reflecting, so that the level of combustion instabilities can be controlled (Martin et al. 2006). The frequency of the mode is tuned by adjusting the length of the chamber and the amplitude of the oscillation is controlled through the value of the reflection coefficient $R_{K}$ (equation (2.10)). The only information available experimentally to characterize acoustics was the existence 

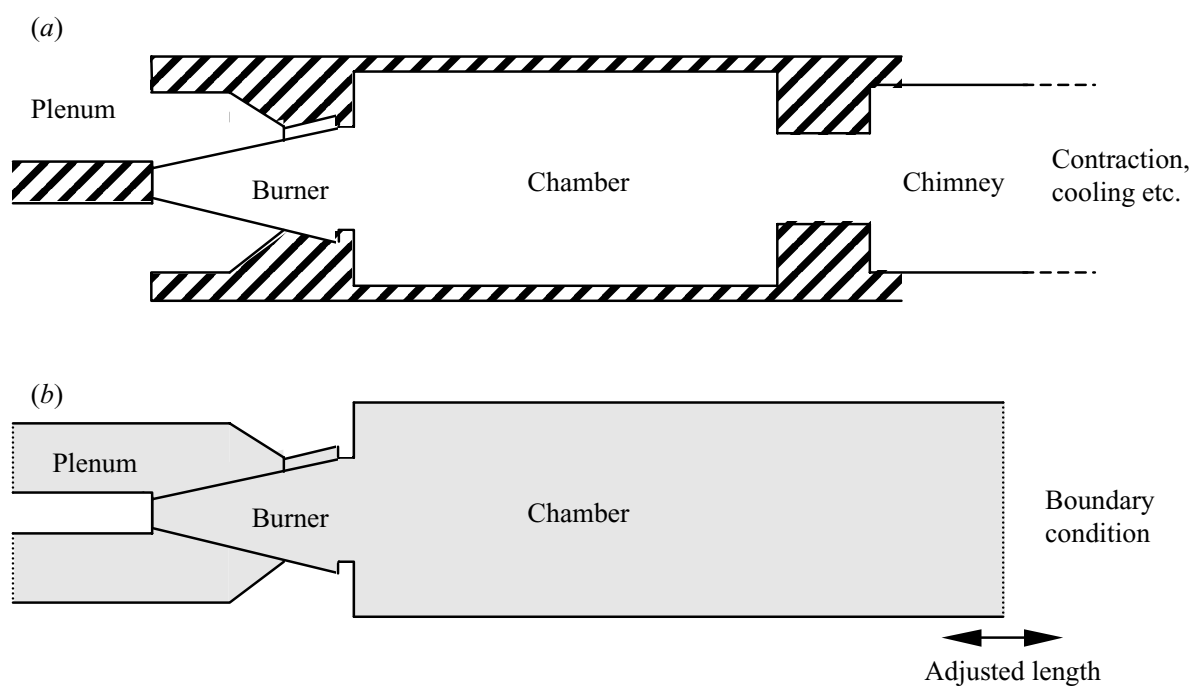

FIGURE 8. Schematic of the combustion geometries: $(a)$ experimental setup (solid parts are hatched); (b) LES setup (the computational domain is in grey).

$\begin{array}{lcccc} & \text { Non-reactive } & \text { Case 1 } & \text { Case 2 } & \text { Case 3 } \\ \text { Cooling processes } & \text { Yes } & \text { No } & \text { Yes } & \text { Yes } \\ \text { Partially reflecting outlet } & \text { No } & \text { No } & \text { No } & \text { Yes } \\ R_{K} & 0.00 & 0.00 & 0.00 & 0.60\end{array}$

TABLE 4. Reflection coefficient of outlet boundary for cases 1 to 3 and the non-reactive simulation.

of a $250 \mathrm{~Hz}$ mode which is probably an eigenmode of the chimney. This value was used as a target to tune the outlet condition in the LES for case 3.

The last column in tables 2 and 3 presents the relaxation factor $K$ (from equation (2.10)) of each boundary. For the main inlet and the outlet, it is relatively low. In combination with a zero reflection parameter $\left(R_{K}\right)$, this results in acoustically nonreflecting boundaries in the frequency range of interest $(50 \mathrm{~Hz}<f<1000 \mathrm{~Hz}$; see equation (2.11)). As seen in table 4, this applies to cases 1 and 2 and the non-reactive simulation. Case 3 , however, imposes $R_{K}=0.60$ at the outlet (the inlet remains fully non-reflecting). The length of the combustion chamber is set to $L=11.4 D(L=7.1 D$ for cases 1 and 2 and the non-reactive simulation). These parameters were chosen in an iterative manner: $R_{K}$ and $L$ were adapted in order to match frequency, axial velocity fluctuations and heat release fluctuations observed in the experiment. The fuel injections are acoustically reflecting over the entire frequency range of interest.

\section{Experimental setup for combustion diagnostics}

The experimental setup for the presented phase-resolved $\mathrm{OH}$ chemiluminescence measurements consists of an optical component and a triggering unit based on the measured dynamic pressure. For optical diagnostics the pressure vessel and the combustion chamber are equipped with large quartz windows, the outer ones being 
exposed to the pressure and intermediate-to-low temperature, the inner ones to high temperature but only moderate pressure gradients. The line of sight integrated $O H^{*}$ emission signal was detected using an image-intensified CCD camera (Pi Max 512 UV, Princeton Instruments) equipped with an achromatic $f / 2$ UV lens with $100 \mathrm{~mm}$ focal length (B. Halle Nachfl.) and an interference filter centred at $312 \mathrm{~nm}$ with a $20 \mathrm{~nm}$ bandwidth. The optical setup allowed for imaging of the complete flame from the axis parallel to the shift direction of the half cones of the burner (i.e. from the top in figure 7). The integration time for collecting sufficiently high signal levels was set to $32 \mu \mathrm{s}$, thus clearly below the time scale of the periodic fluctuations. Images were corrected for background and the sensitivity distribution of the CCD camera.

For the determination of the dynamic pressure the combustion chamber was equipped with a pressurized microphone (probe microphone 4182, Brüel \& Kjaer) connected to the downstream part of the combustion chamber and a pressure transducer (Type 4043A10, Kistler) close to the burner front panel. Both devices typically showed a similar behaviour, so the signal from either of them could be used as external trigger of a delay generator (DG535, Stanford Research Systems) after adequate filtering. The output of this unit, delayed in steps of $45^{\circ}$, served as input trigger for the ICCD.

\section{Non-reactive flow results}

This section presents the results of the non-reactive simulation. The outlet boundary is non-reflecting (table 4). The mass fluxes and temperatures are specified in table 3 .

\subsection{Velocities}

The burner described was tested in a water channel at Alstom, Switzerland. Figure 9 compares PIV results (at Reynolds number 109000) with the results of the nonreactive LES (at Reynolds number 68000) in a cut through the chamber and burner at $y / D=0$. The Reynolds numbers are based on the burner exit diameter $D$ and the mean velocity at the burner exit $u_{\text {ref }}$. The chamber is seen at the top of the four graphs, the burner at the bottom. The axial and radial mean velocity cuts show good agreement with the experiment. The central recirculation zone extends well inside the burner. Axial and radial velocity fluctuations agree remarkably well with experiment. Only at $x / D=-0.75$ do the measurement and simulation disagree: this is due to PIV difficulties in the upstream part of this burner, which is very small.

\subsection{Mixing}

Mixing was evaluated in the water channel by acetone laser-induced fluorescence (LIF). Measurements were conducted in planes of constant $x$-coordinates inside the burner. They are directly compared to fuel mass fraction from the LES in figure 10, where only the results at $x / D=-0.18$ are presented. LES is displayed at the top of the figure, the experiment at the bottom, mean values on the left, standard deviations on the right. The mean values show a relatively strong asymmetry for the LES. The coarse mesh near the fuel injections ( 5 cells for one hole diameter) influences the trajectories on each side of the burner differently. A simulation with the specification of resolved turbulence at the plenum inlet (not shown here) slightly improves symmetry, but gives quite similar mixing predictions since most of turbulence is created inside the domain. Nonetheless, the overall mean concentrations are comparable. LES and experiment are remarkably close for standard deviations where strong fluctuations in the trajectory of the injections is seen. 


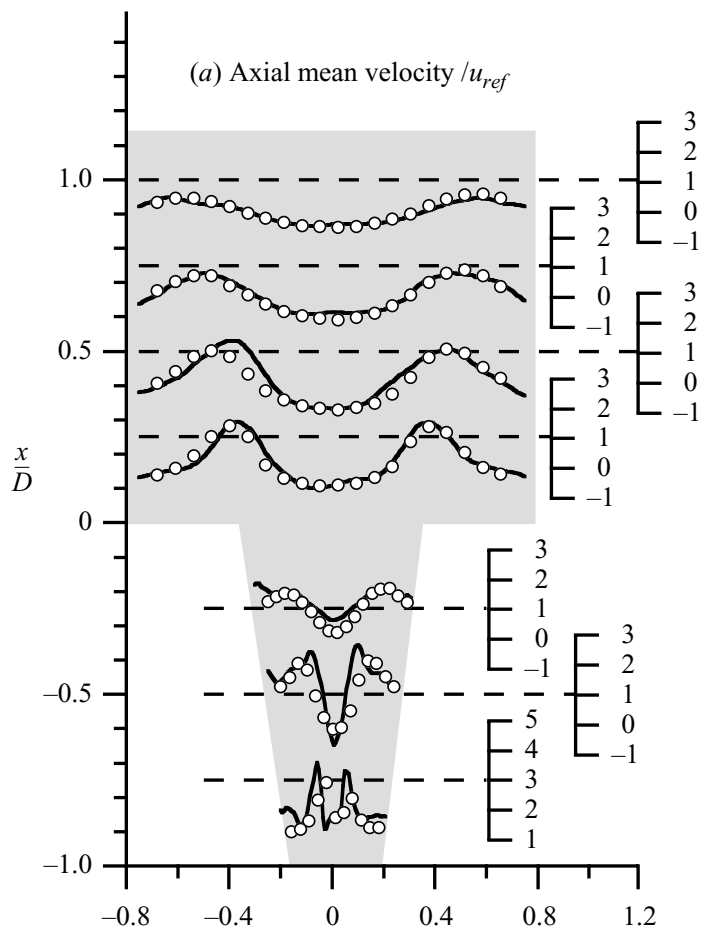
(b) Radial mean velocity $/ u_{\text {ref }}$
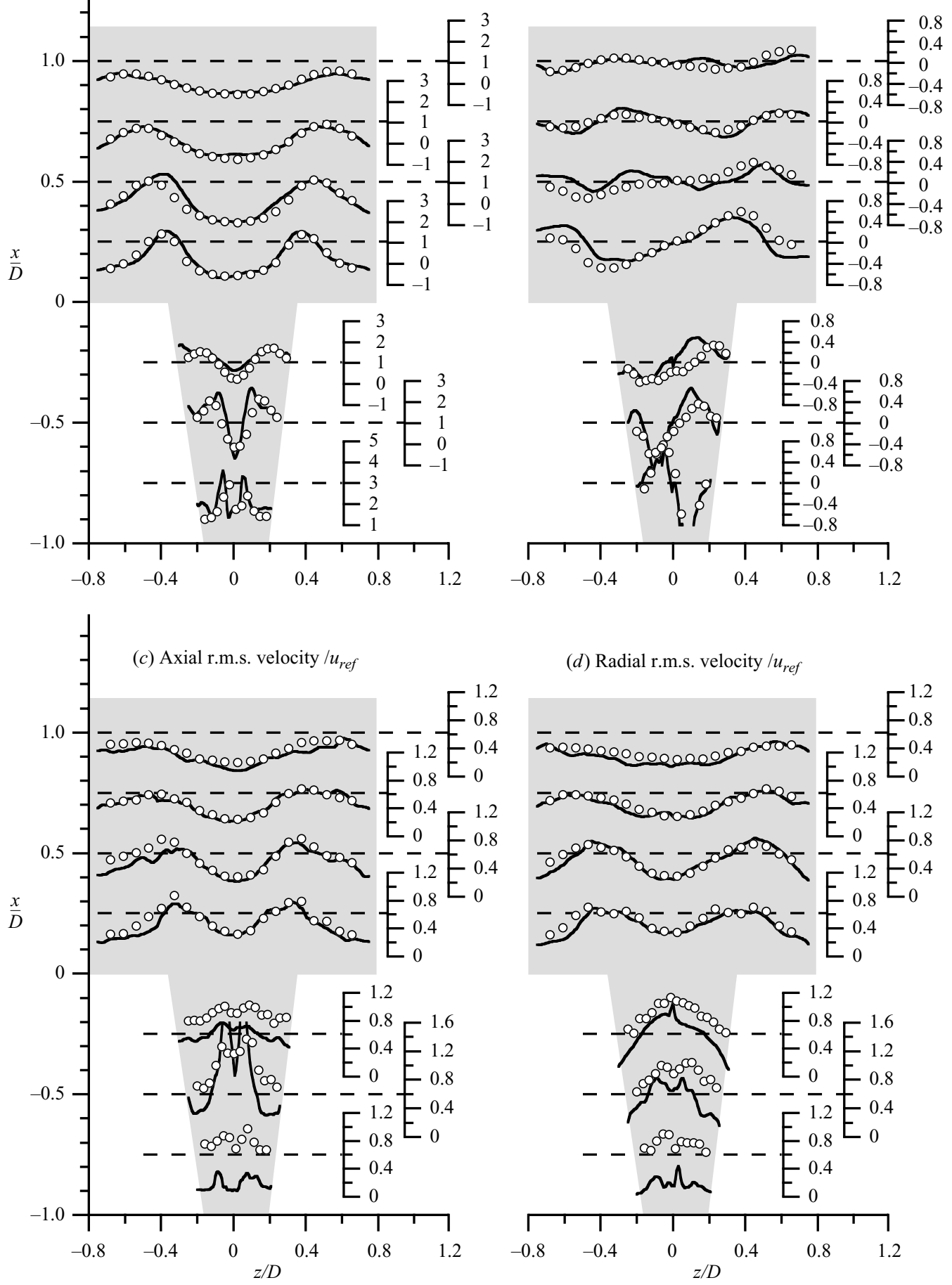

(d) Radial r.m.s. velocity $/ u_{r e f}$

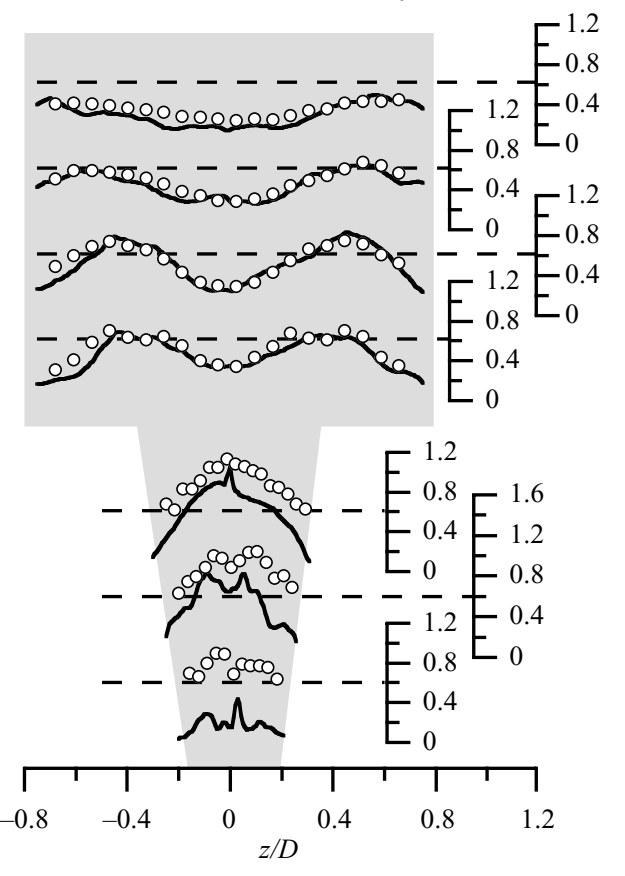

FIGURE 9. Comparison of the velocity fields from experiment (circles) with the non-reactive simulation (- $)$. 

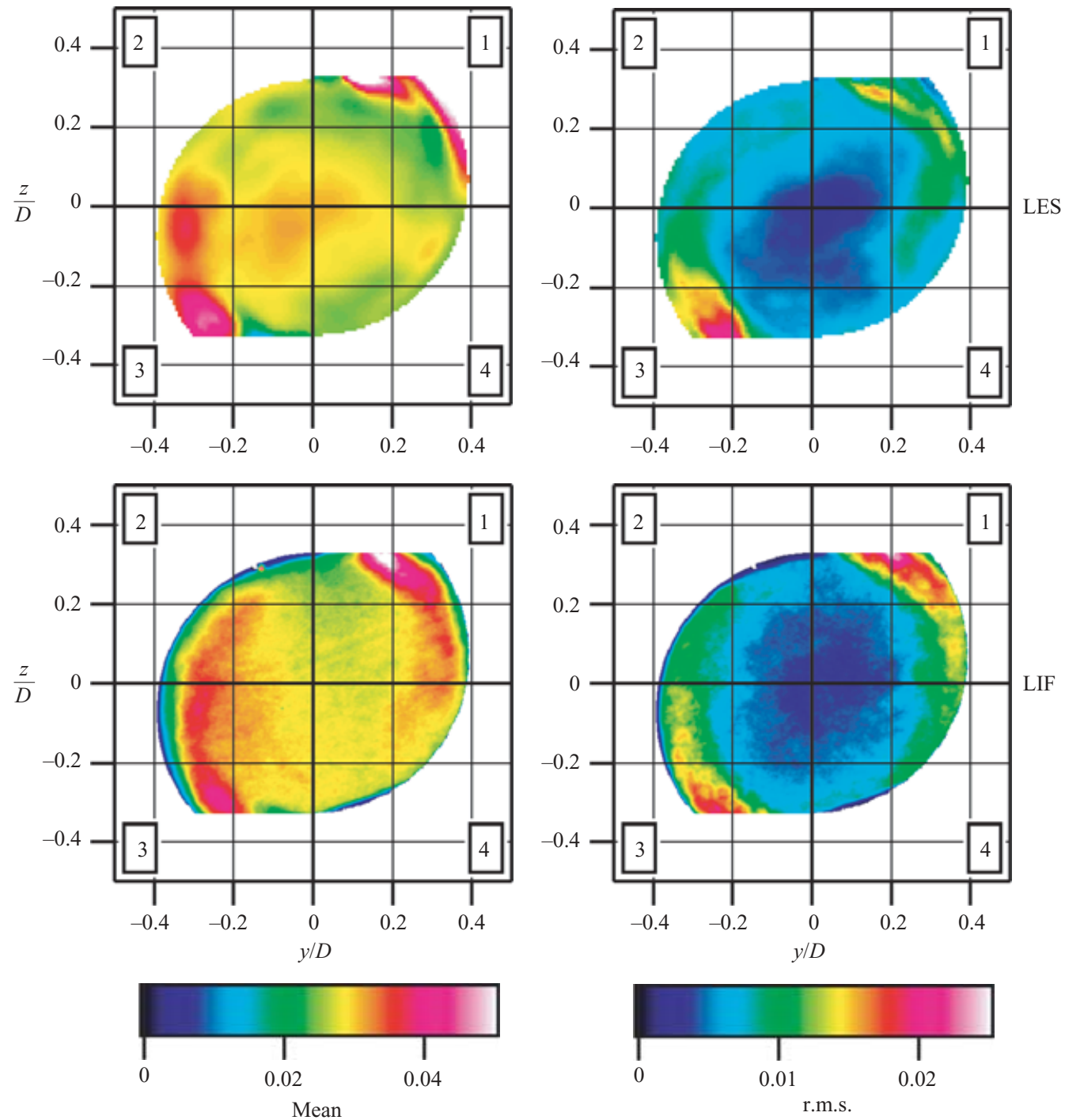

FIgURE 10. Comparison of the mean fuel mass fraction (left) and the fuel mass fraction standard deviation (right) from experiment (bottom) with data from the LES (top) at $x / D=-0.18$. Non-reactive case.

The results of figure 10 can certainly be improved by computations on a finer mesh or by using a higher-order numerical scheme, but it is considered that they are sufficiently good to continue with the simulation of an aerodynamically stabilized flame.

\section{Reactive flow results}

This section presents the results of the three different simulations with combustion (table 4) and compares them to experiment (all at a Reynolds number of 68000 ). The first simulation (case 1) neglects the effects of cooling air and heat losses by radiation and convection. The second simulation (case 2) includes all cooling air and 


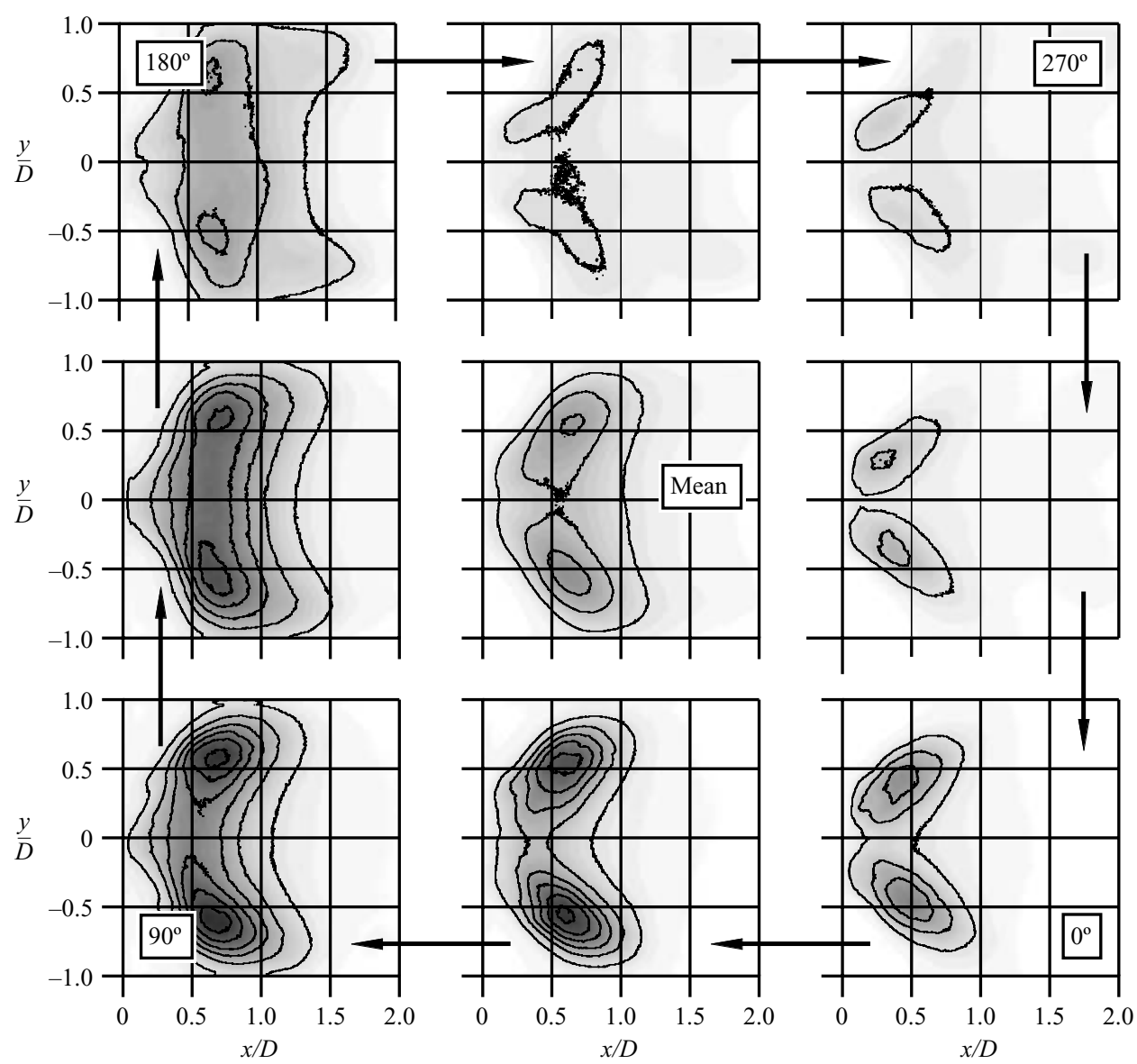

FIGURE 11. Phase-averaged integrated $\mathrm{OH}$ chemiluminescence from the experiment. The global mean is shown in the middle of the figure. Experimental data.

heat transfer and has a non-reflecting outlet while the third simulation (case 3) has a partially reflecting outlet (compared to the non-reflecting outlets of cases 1 and 2), which leads to a larger acoustic activity. The mean mass fluxes and inlet temperatures are specified in tables 2 and 3 .

\subsection{Flame position and shape}

Reactive flow experiments were performed on a medium-pressure test rig at DLR, Stuttgart. A strong combustion instability at $f=250 \mathrm{~Hz}$ was observed for the regime considered here (table 3). Phase-averaged measurements of $\mathrm{OH}$ chemiluminescence are presented in figure 11. The reference signal for phase averaging comes from a microphone probe close to the flame. The burner exit is located at $x / D=y / D=0$. The burner itself, located at $x / D<0$, is not seen. As the naturally excited $\mathrm{OH}$ radical is measured, the views are integrated over the whole flame in the $z$-direction. The middle picture displays the overall mean (averaged over all phases). At phase angle $\varphi=270^{\circ}$, heat release is very low, whereas at $\varphi=90^{\circ}$ it is very intense.

As expected, the simulations with the non-reflecting outlet (cases 1 and 2) do not exhibit any combustion instability. Nonetheless, the mean heat release 

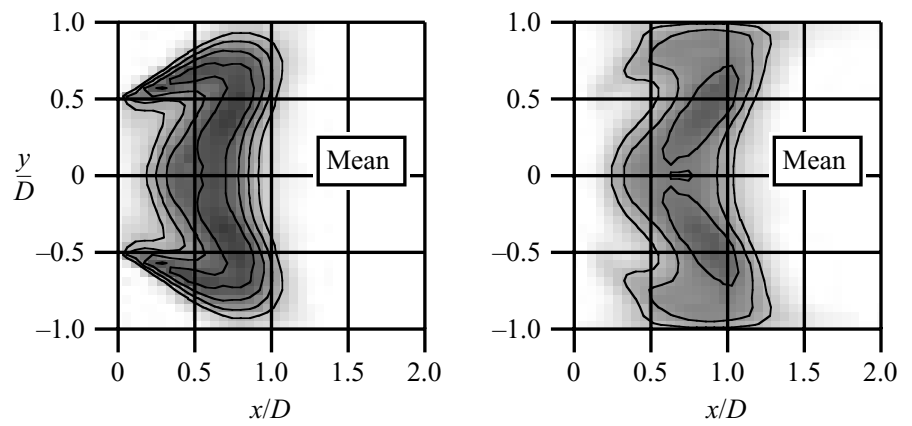

FIGURE 12. Integrated heat release from case $1(a)$ and case $2(b)$. LES data.

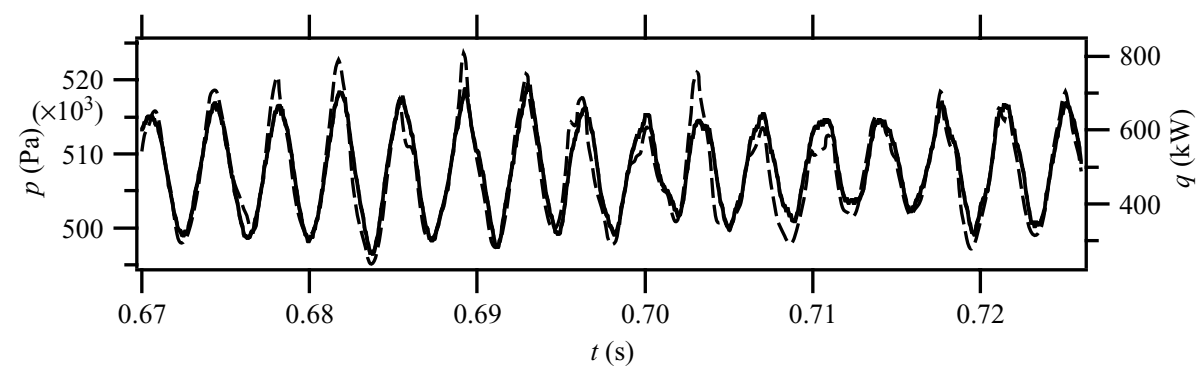

FIGURE 13. Local chamber pressure $p(-)$ at $x=D, y=z=0$ and global heat release $q$ $(--)$ versus time $(t)$ for case 3 .

(integrated in the same line of sight as the experiment) can be compared to the $\mathrm{OH}$ chemiluminescence (Poinsot et al. 1987), and is presented in figure 12: case 1 is shown on in $(a)$, case 2 in $(b)$. These images must be compared to the image in the middle of figure 11. Note that for all heat release images, the scales are identical and linear but arbitrary as no quantitative comparison with the $\mathrm{OH}$ chemiluminescence is possible for such a partially premixed regime. In case 1, the flame is stabilized by the centre and the corner recirculation zones, while the experiment indicates that the stabilization should only be provided by the central recirculation zone (figure 11 centre). This is true for case 2. Its heat release field (figure 12b) compares well with the $\mathrm{OH}$ chemiluminescence (figure 11 centre). This confirms that including cooling processes in the LES is essential for obtaining the right flame stabilization.

The simulation of case 3 exhibits a combustion instability at $f=275 \mathrm{~Hz}$ which is close to the $250 \mathrm{~Hz}$ observed in the experiment. A total simulation time of $56 \mathrm{~ms}$ was run, corresponding to 15 cycles of oscillations during which phase averaging was performed. Pressure and global heat release oscillate almost in phase (figure 13). Figure 14 shows phase-averaged integrated heat release images for this case. As for the experiment, a pressure signal close to the flame was used as trigger. The phase reference $\left(\varphi=0^{\circ}\right)$ corresponds to a zero crossing of pressure with positive slope. The whole cycle is comparable to the experimental cycle (figure 11). The same strong fluctuations are seen: at $\varphi=270^{\circ}$, very low heat release is observed, whereas at $\varphi=90^{\circ}$, maximum heat release occurs. Note that every phase-averaged image obtained from LES is based on 15 snapshots (one for each cycle). This explains the high level of noise in the images. The mean heat release image in the middle of figure 14 also comes very close to the experimental image (figure 11 centre). 


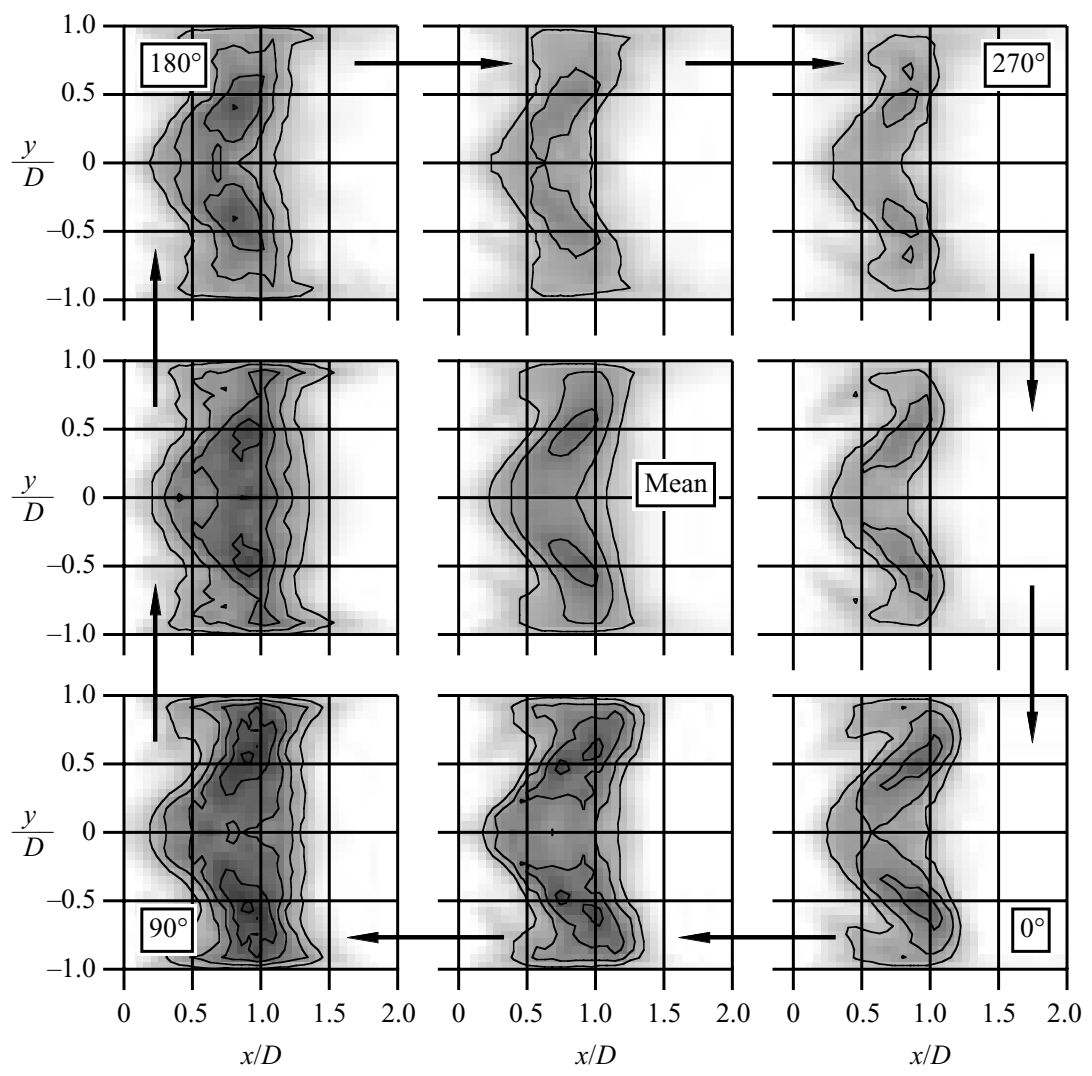

FIgURE 14. Phase-averaged integrated heat release from case 3. The global mean is shown in the middle of the figure.

\subsection{Flame regime}

Figure 15 displays scatter plots of heat release versus local equivalence ratio $\phi$. This diagnostic allows the identification of the regime at which combustion takes place locally: diffusion flamelets would produce peaks around $\phi=1$. Here all points are located around the mean value $\phi=0.54$, demonstrating that all flame elements burn as lean partially premixed flames. Even though methane and air are injected separately in the burner, mixing is fast and most flame zones correspond to lean combustion in a partially premixed regime. This justifies the use of a chemical scheme valid only from $\phi=0.4$ to 1.1: for such lean flame elements figures 2 and 3 show that the reduced chemistry is very accurate.

\subsection{Velocities}

In the experiment, velocity fields were measured with PIV. They are presented in figure 16 in a cut through the chamber and burner $(z / D=0)$. Again, the chamber is seen at the top of the four graphs, the burner at the bottom. The plots clearly show the central and corner recirculation zones and the strong turbulence levels. All simulations (cases 1 to 3 ) show good agreement with the experimental data, for both radial and axial mean velocity (figure $16 a, b$ ). The only notable difference is the slightly different position of the central recirculation zone inside the burner for case 1 . Axial fluctuations are predicted well, too (figure 16c). For the radial fluctuations, all 

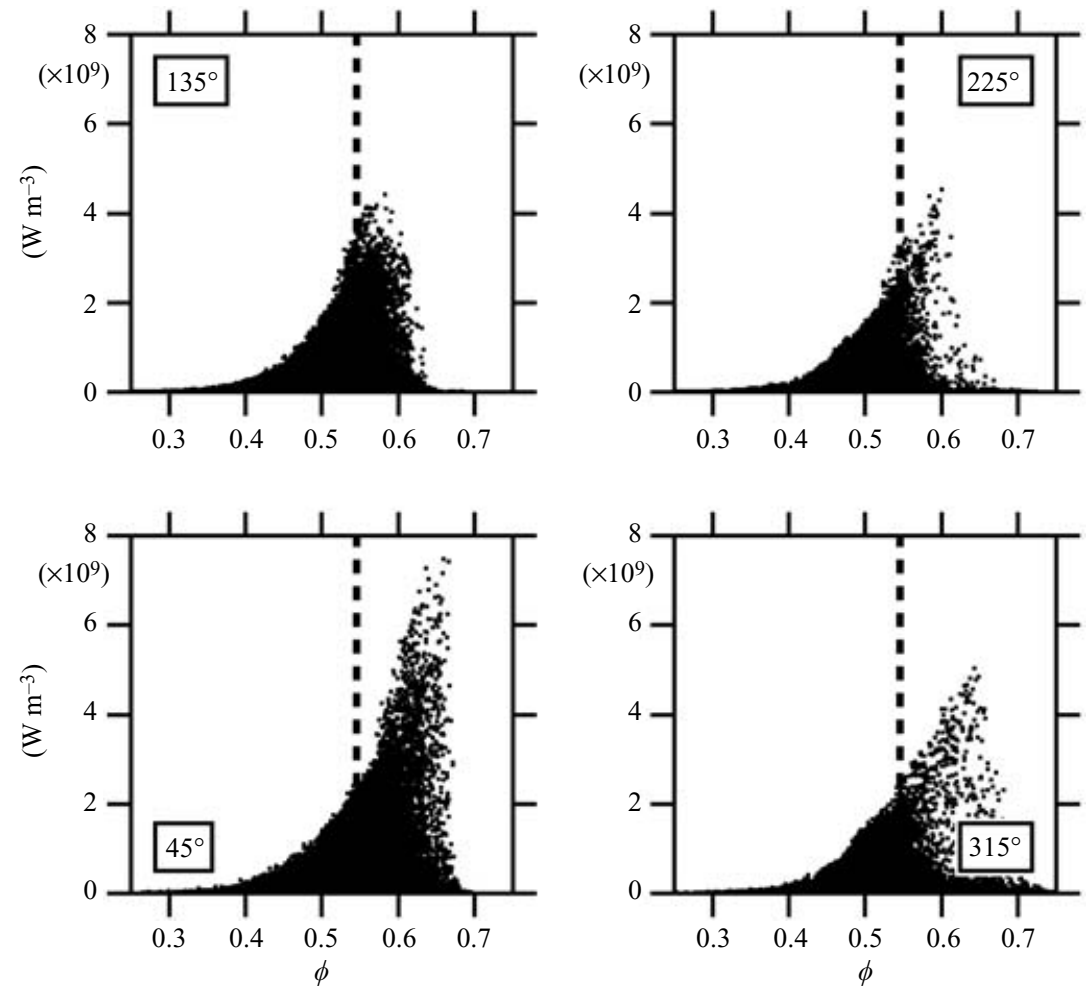

FIGURE 15. Heat release per unit volume versus equivalence ratio at four different phase angles for case 3 . The mean equivalence ratio is indicated by the dashed line.

three LES predict stronger fluctuations in the shear layer just after the burner exit and close to the chamber wall at the downstream location (figure 16d). For these time-averaged fields, the influence of pressure oscillation seems small: cases 1, 2 and 3 lead to very similar results in terms of velocity field. The next section shows a very different conclusion for NO levels.

\subsection{Heat losses, temperature and NO}

The total flame power is approximately $480 \mathrm{~kW}$ for all three cases. For cases 2 and 3, the average radiation losses are $39 \mathrm{~kW}$ and the convection losses $29 \mathrm{~kW}: 8 \%$ of the total power is lost by radiation and $6 \%$ by convection. For case 3 the total thermal losses are presented in figure 17 as a function of the phase angle $\varphi$ : they do not depend strongly on the phase angle and their mean values are identical to the ones observed in case 2 .

The heat losses that sum to $14 \%$ of the total power for cases 2 and 3 influence strongly the temperature distribution in the combustion chamber. Figure 18 (upper curves) shows averaged temperature profiles (integrated in time and in the $y$ - and $z$-directions) versus $x$ (chamber axis in figure 7 ). The adiabatic simulation (case 1 ) reaches the adiabatic flame temperature at $x / D=1$. Neither case 2 nor 3 reaches the adiabatic flame temperature $(1850 \mathrm{~K})$ locally. At the chamber outlet $(x=5.7 D)$, the temperature is down to $1685 \mathrm{~K}$. From experiment, only temperature measurements at the chimney inlet are available $(1500 \mathrm{~K})$. As the chimney is not included in the simulation, this is only of limited value, but confirms the important heat loss level. 


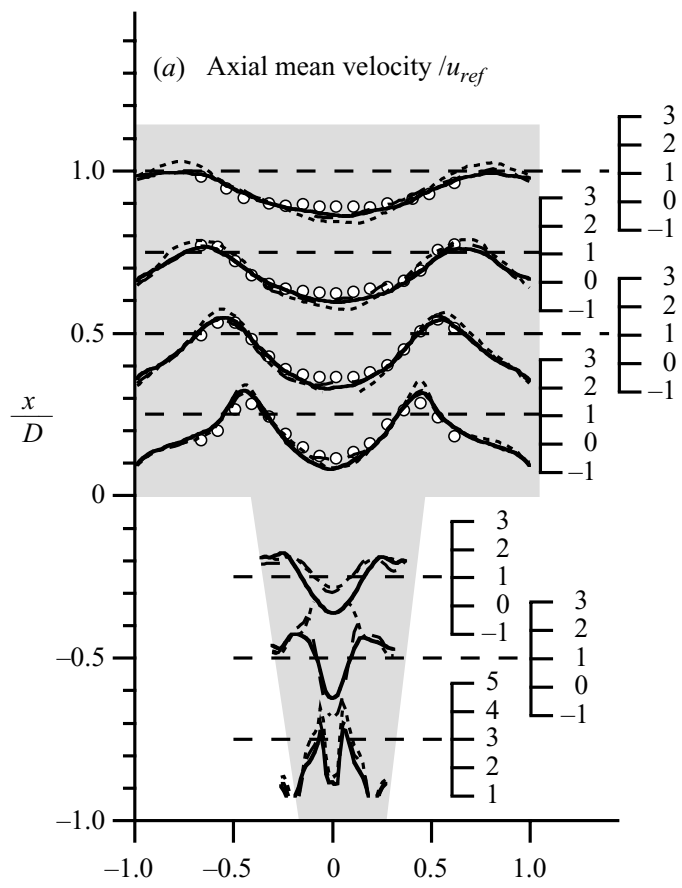

(b) Radial mean velocity $/ u_{\text {ref }}$
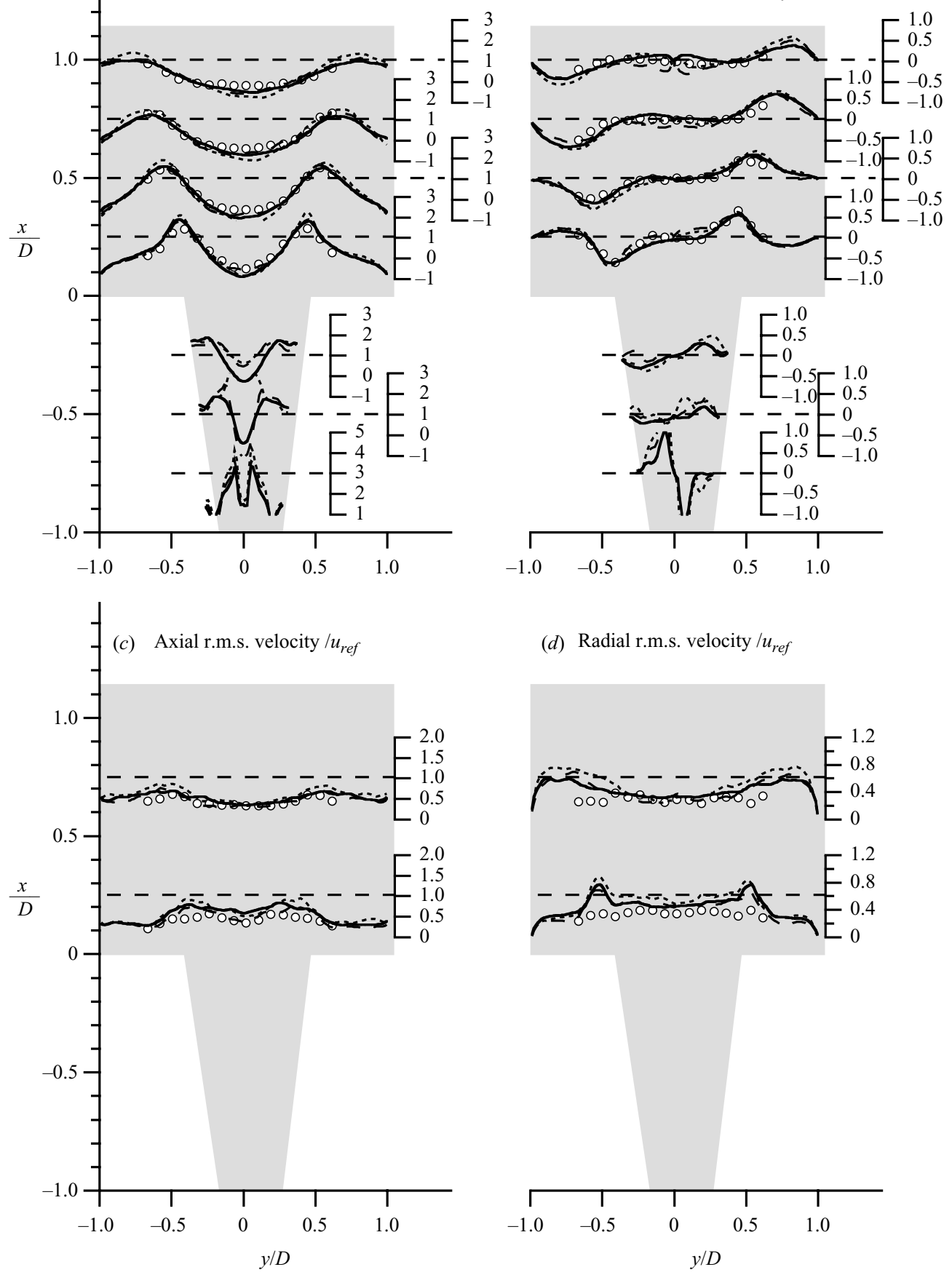

(d) Radial r.m.s. velocity $/ u_{r e f}$

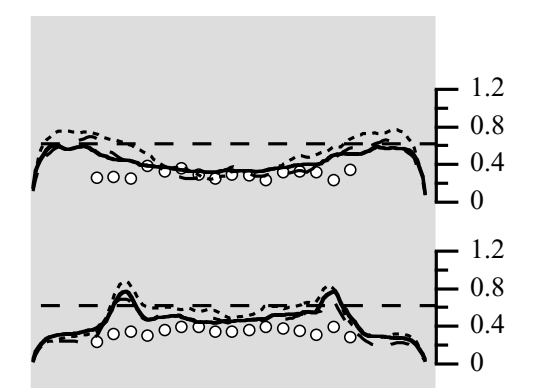

FIgURE 16. Comparison of velocity fields. Experiment (circles) and reactive simulations $(---$, case $1 ;---$, case $2 ;-$, case 3$)$.

Figure 18 also presents averaged values for NO volume fraction (lower curves). Case 1 shows a strong amount of thermal NO after the flame. Its concentration increases continuously with downstream abscissa due to the high temperature. At 


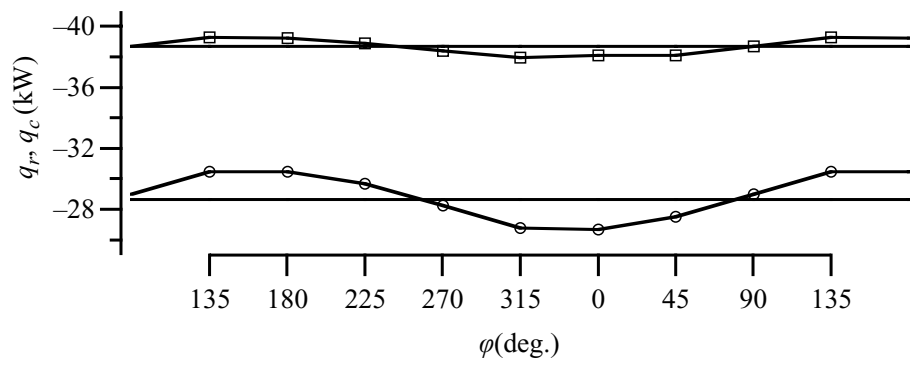

FIGURE 17. Radiation ( $q_{r}$, squares) and convection ( $q_{c}$, circles) heat losses as a function of the phase angle $\varphi$. LES results (case 3 ).

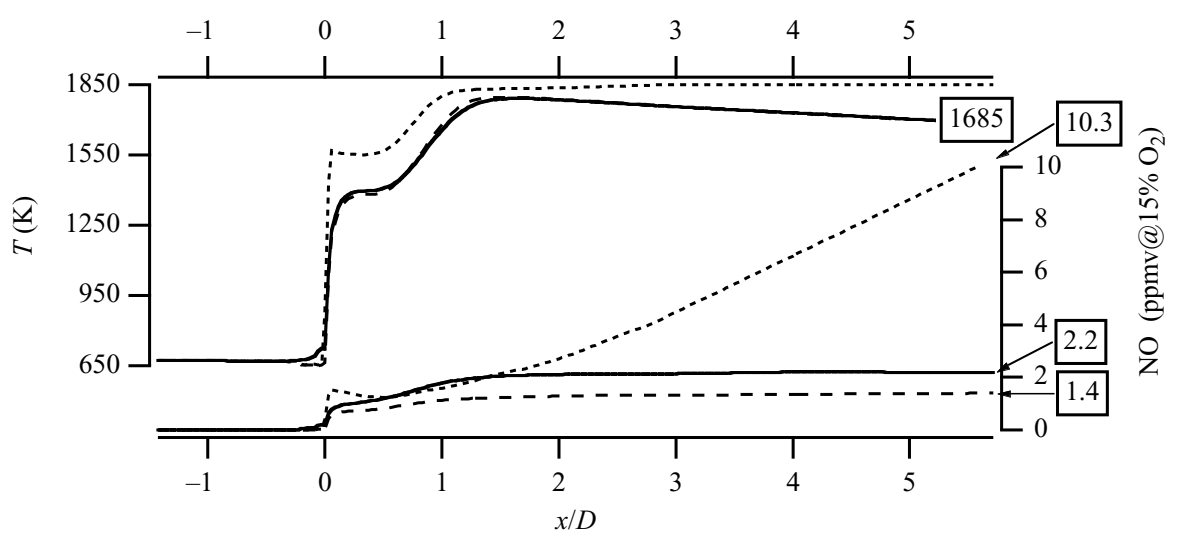

FIGURE 18. One-dimensional temperature $T$ (top) and NO curves (bottom) for the three reactive cases $(----$, case $1 ;---$, case 2 ; - , case 3$)$.

$x=5.7 D$ a $\mathrm{NO}$ concentration of $10.3 \mathrm{ppmv} @ 15 \% \mathrm{O}_{2}$ is found. For cases 2 and 3 almost no thermal NO production after combustion is observed. The temperatures are sufficiently low to stop its production. For case 2 a $\mathrm{NO}$ concentration of 1.4 ppmv@ $15 \% \mathrm{O}_{2}$ is found and case 3 produces 2.2 ppmv@ $15 \% \mathrm{O}_{2}$ of $\mathrm{NO}$. (The experiment gave values of the order of 25 ppmv@ $15 \% \mathrm{O}_{2}$. This error is most likely due to the measurement apparatus.) The differences between the three cases give useful insight into the NO formation process. The impact of heat transfer on thermal NO (comparing case 1 to case 2) is evident. Understanding the differences between cases 2 (stable combustion) and 3 (unstable combustion) is more complicated. As the temperature profiles for both are nearly identical (figure 18) and since the NO concentration for case 3 is higher, there must be stronger temperature fluctuations for case 3. How this happens will be analysed in the following sections.

\subsection{Acoustic balance}

The previous section has shown that pressure oscillation (case 3) can lead to a $50 \%$ increase of outlet NO level compared to stable combustion (case 2). The obvious conclusion at this stage is that NO will be strongly affected by oscillating pressure and that understanding combustion stability becomes a key issue not only for combustion operability (vibrations, possible quenching, etc.) but also for precise emission predictions. This section shows how the classical Rayleigh criterion (Rayleigh 1878) can be now extended using LES. 


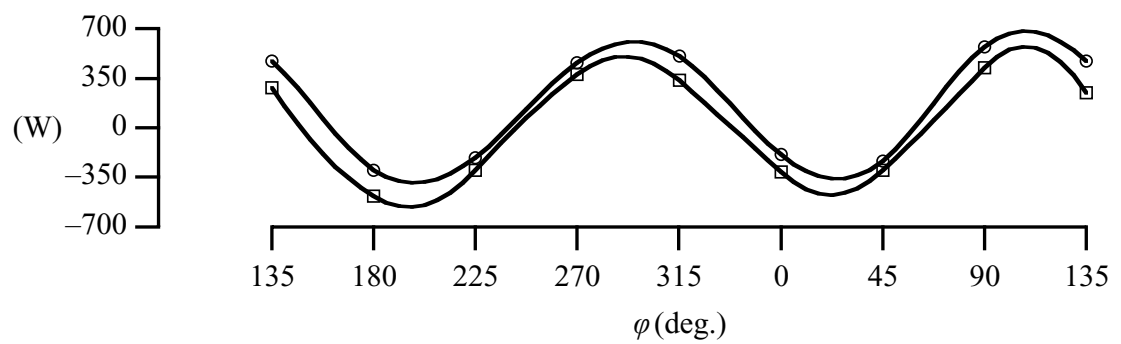

FIGURE 19. Verification of the acoustic balance by comparing the two sides of (6.1): circles, $\mathscr{S}_{1}-\mathscr{F}_{1} ;$ squares, $\mathrm{d} \mathscr{E}_{1} / \mathrm{d} t$.

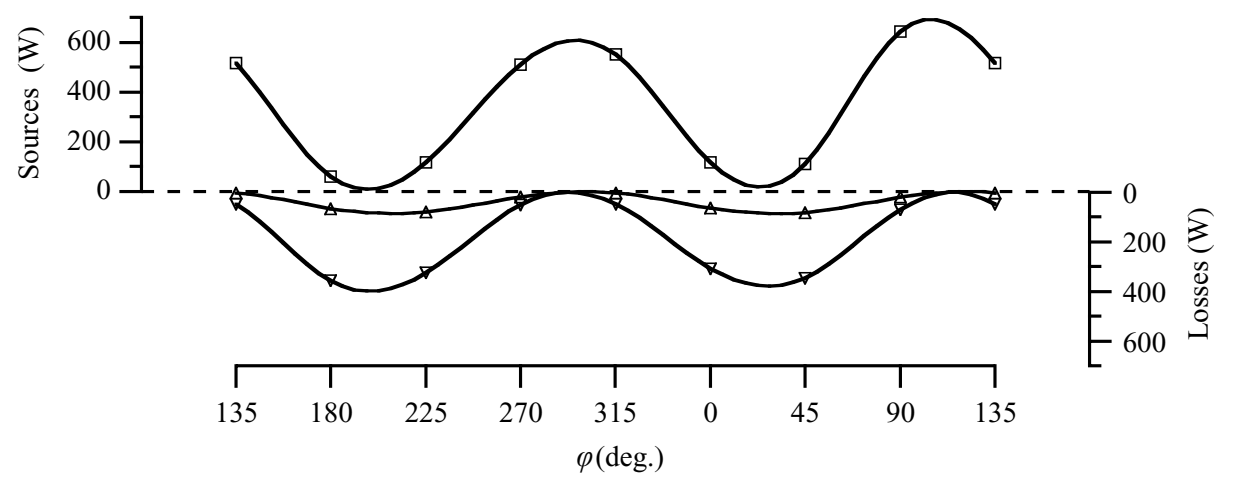

FIGURE 20. The right-hand-side terms of equation (6.1): squares, $\mathscr{S}_{1}$; down triangles, $\mathscr{F}_{1}$; up triangles, $\mathscr{F}_{1}$ from inlet only.

The Rayleigh criterion states that if pressure and heat release are positively correlated, combustion instability occurs. Figure 13 displays a local pressure trace and the total heat release versus time and shows that case 3 satisfies this requirement. But Rayleigh's term $\left(\iint p q \mathrm{~d} t \mathrm{~d} V\right)$ is not the only contribution to acoustics in such a configuration (Poinsot \& Veynante 2005; Martin et al. 2006). Typically, a limit cycle is reached when the Rayleigh term and the losses at the boundaries and dissipation losses balance. As defined in Poinsot \& Veynante (2005), the Rayleigh source term is denoted $\mathscr{S}_{1}$, acoustic fluxes at the boundaries $\mathscr{F}_{1}$ and the total acoustic energy in the domain $\mathscr{E}_{1}$. The following balance equation should hold:

$$
\frac{\mathrm{d}}{\mathrm{d} t} \mathscr{E}_{1}=\mathscr{S}_{1}-\mathscr{F}_{1} .
$$

All components were computed from the phase averages of case 3. Figure 19 compares the right-hand and left-hand sides of equation (6.1). The agreement between these two terms shows that the acoustic energy budget is closed and that equation (6.1) provides a good evaluation of all terms controlling the acoustic energy in the combustor. Now, a close examination of figure 19 reveals that this agreement is not perfect. $\mathrm{d} \mathscr{E} 1 / \mathrm{d} t$ is smaller than $\mathscr{S}_{1}-\mathscr{F}_{1}$ by a constant value of the order of $150 \mathrm{~W}$. This discrepancy is not explained at this point and could be due to the linearization of the conservation equation or to the fact that dissipation was not included in equation (6.1).

The right-hand-side terms of equation (6.1) are plotted in figure 20. The source term $\left(\mathscr{S}_{1}\right)$ is plotted in the top half of the graph, and all sink terms in the bottom half $\left(\mathscr{F}_{1}\right)$. The acoustic losses at the inlet (up triangles) are small compared to the 


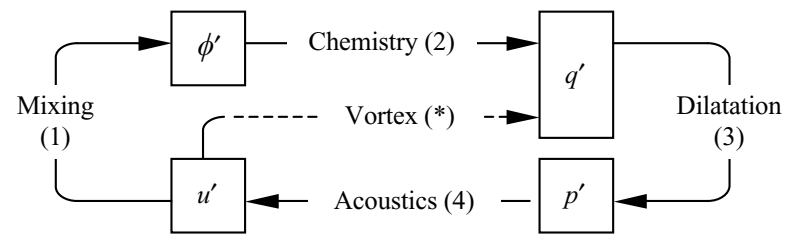

FIGURE 21. Links between different quantities in typical gas turbine combustion instability.

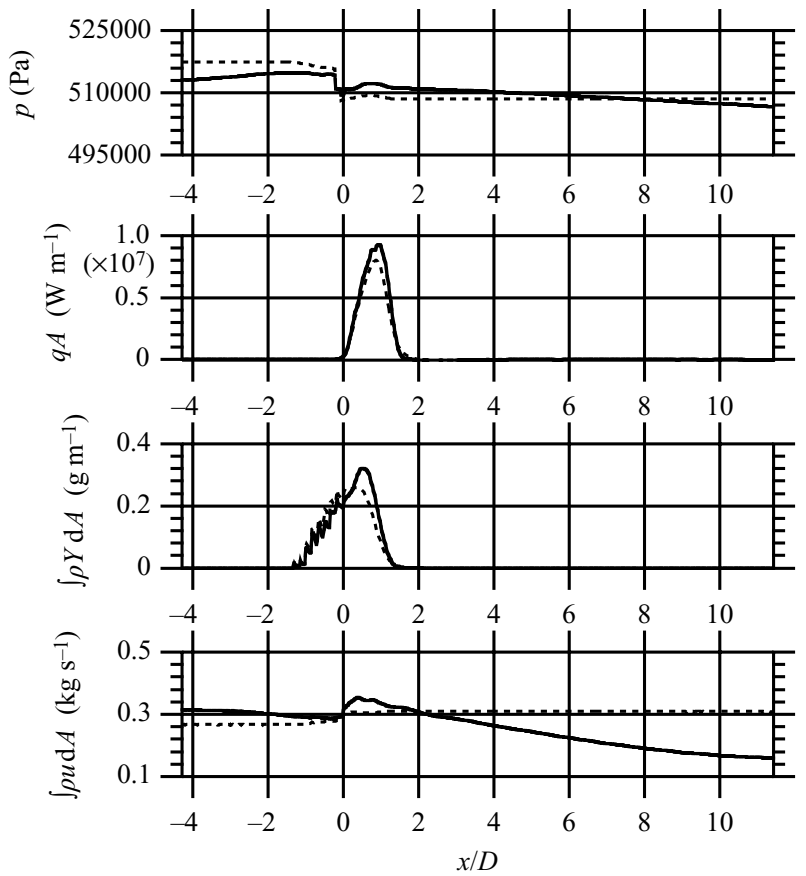

FiguRE 22. One-dimensional integrated graphs of pressure $p$, heat release $q$, fuel mass $\int \rho Y \mathrm{~d} A$ and total mass flux $\int \rho u \mathrm{~d} A$ for $\varphi=45^{\circ}$ (from top to bottom). Curves: —, instantaneous; - - - , mean.

total boundary losses, which are dominated by the outlet losses. Figure 20 shows that the Rayleigh term (squares) is always positive and therefore always exciting the $275 \mathrm{~Hz}$ mode. However, two moments in the cycle (phases $290^{\circ}$ and $110^{\circ}$ ) correspond to maximum acoustic forcing by combustion. The acoustic losses term $\left(\mathscr{F}_{1}\right.$, down triangles in figure 20) reach maximum values around $200^{\circ}$ and $20^{\circ}$, which is a quarterperiod after the moments of maximum $\mathscr{S}_{1}$ terms. The acoustic losses term $\mathscr{F}_{1}$ plays an important role in the limit cycle: it evacuates (at phases $200^{\circ}$ and $20^{\circ}$ ) the acoustic energy created by the Rayleigh term (at phases $290^{\circ}$ and $110^{\circ}$ ). It also controls the amplitude of the limit cycle.

\subsection{Instability mechanism}

The mechanism leading to instability can be summarized as shown in figure 21 . It is illustrated here by phase- and plane-averaged ( $y$ - and $z$-direction) plots of pressure, heat release, fuel mass and global mass flux (figures 22 to 25). The mean values are always included and each figure shows results for one phase angle. Following 

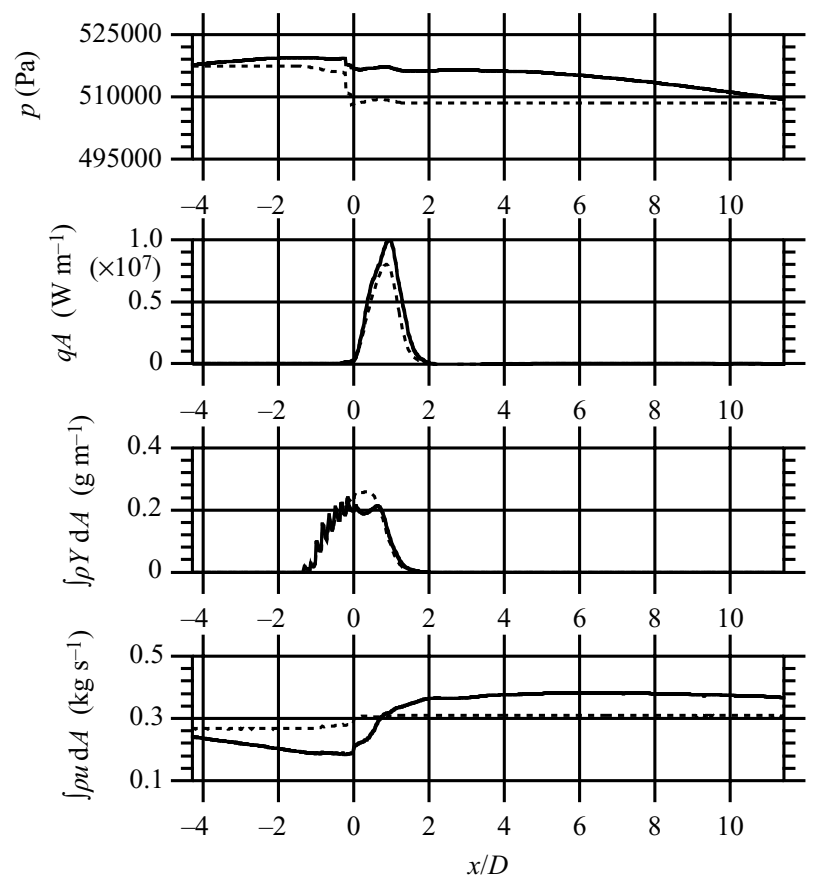

Figure 23. As figure 22 but for $\varphi=135^{\circ}$.

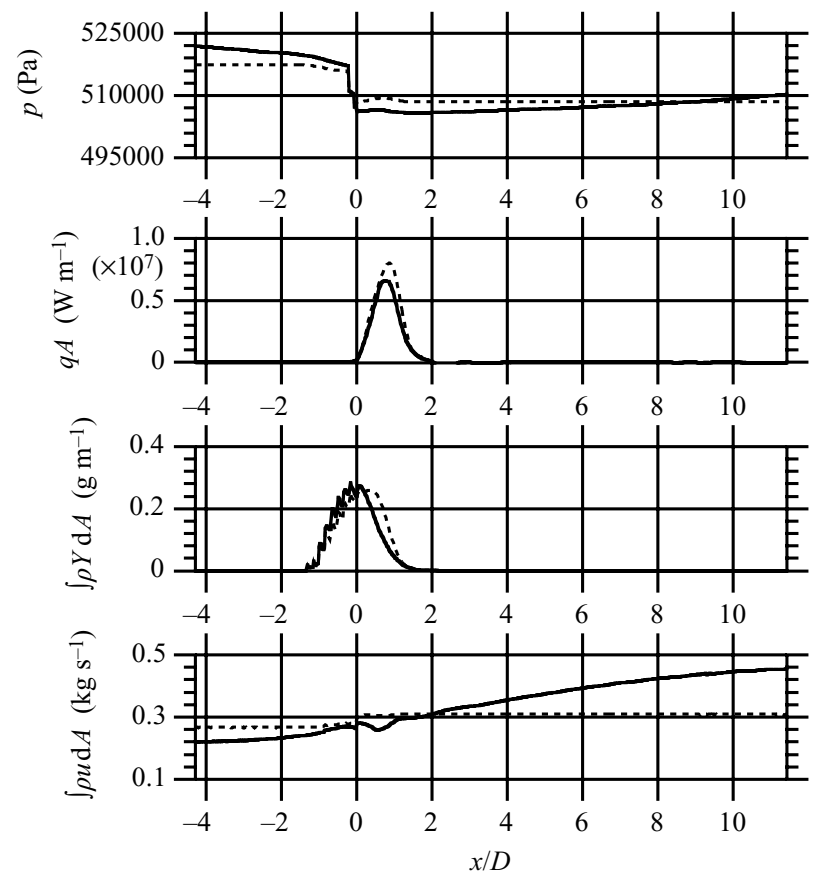

Figure 24. As figure 22 but for $\varphi=225^{\circ}$.

one cycle of the instability allows to understand the instability mechanism to be understood:

Velocity $u^{\prime} \leftarrow$ pressure $p^{\prime}($ mechanism 4 in figure 21): the mean pressure curve (dashed line) shows the pressure loss through the burner; the mean mass flux 


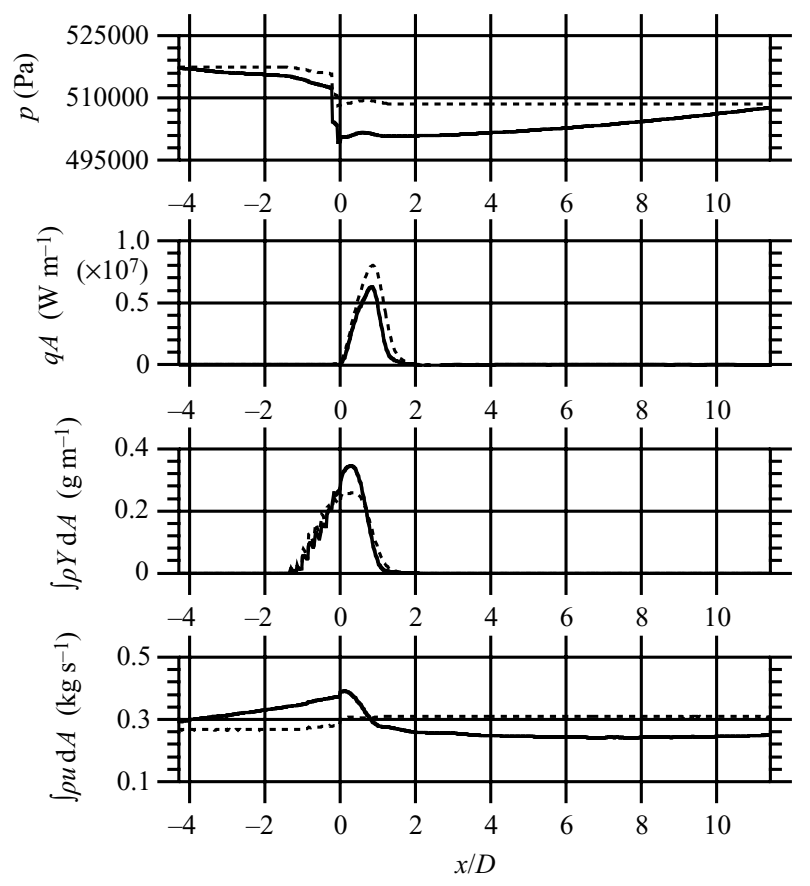

Figure 25. As figure 22 but for $\varphi=315^{\circ}$.

shows that mass is conserved up- and downstream of the fuel and cooling-air injections (figures 22 to 25). The phase-averaged pressure fluctuations indicate that the eigenmode is a quarter-wave mode in the chamber. The instantaneous mass flux is affected by the pressure field: a velocity node is found close to the burner exit and an anti-node is found at the chamber exit.

Pressure $p^{\prime} \leftarrow$ heat release $q^{\prime}$ (mechanism 3 in figure 21): heat release is large for high pressures close to the flame $\left(\varphi=135^{\circ}\right.$, figure 23$)$, and small for low pressures $\left(\varphi=315^{\circ}\right.$, figure 25$)$ : combustion is driving the pressure fluctuations.

Heat release $q^{\prime} \leftarrow$ equivalence ratio $\boldsymbol{\phi}^{\prime}$ (mechanism 2 in figure 21$)$ : the heat release fluctuations are due to local fuel concentrations. From $\varphi=225^{\circ}$ to $\varphi=45^{\circ}$ (figures 24 and 22), a high fuel concentration flow is convected from the burner into the chamber. This pocket burns from $\varphi=45^{\circ}$ to $\varphi=135^{\circ}$ (figures 22 and 23 ).

Equivalence ratio $\boldsymbol{\phi}^{\prime} \leftarrow$ velocity $u^{\prime}$ (mechanism 1 in figure 21$)$ : this fuel pocket causing the strong heat release is formed close to the fuel injections $(x=-D / 2)$, from $\varphi=135^{\circ}$ to $\varphi=225^{\circ}$ (figures 23 and 24). This is due to the low air speed during this period as verified by the mass flux graph.

The mechanism described is well-known (Keller 1995; Lieuwen 2001). Note that the fuel line impedance would also play a significant role: in the present LES, it was set to $\infty$, so that the fuel inlet velocity is fixed, the inlet section is perfectly reflecting and the fuel flow rate into the burner is constant. Changing the impedance of these fuel jets would certainly lead to different stability characteristics.

This mechanism is very effective in closing the instability loop, since the time it takes for the fuel to be convected into the chamber corresponds approximately to half a period of the quarter-wave mode. This process becomes even clearer when looking at snapshots of the simulation during one cycle (figure 26). The burner is cut open in order to give a better view of the fuel injections. They are visualized by equivalence ratio iso-surfaces $(\phi=2)$ and coloured by axial velocity. The flame is visualized by a 

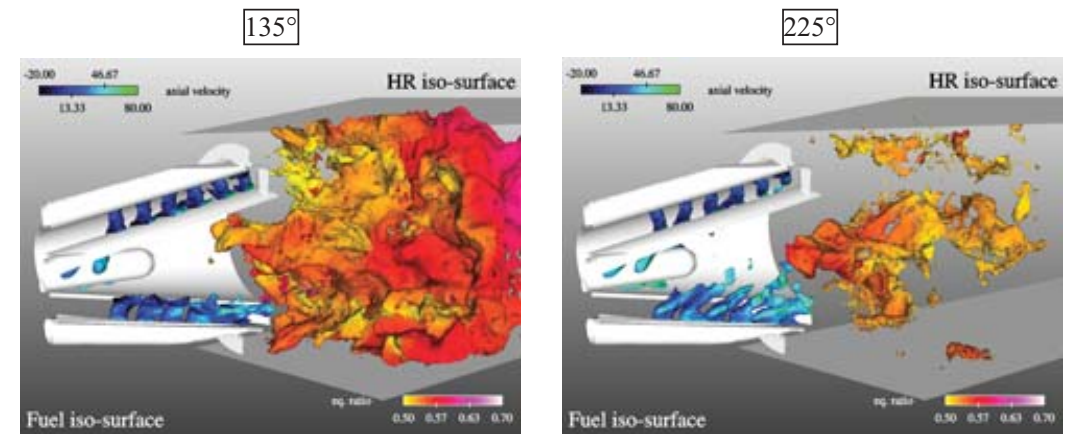

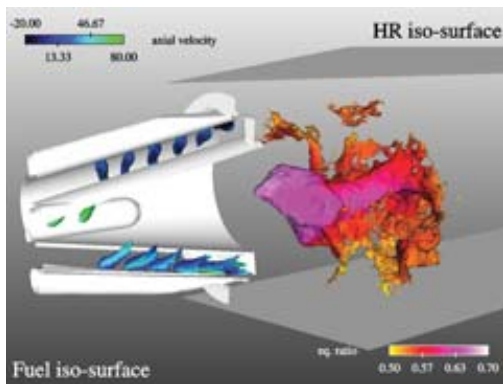

$45^{\circ}$

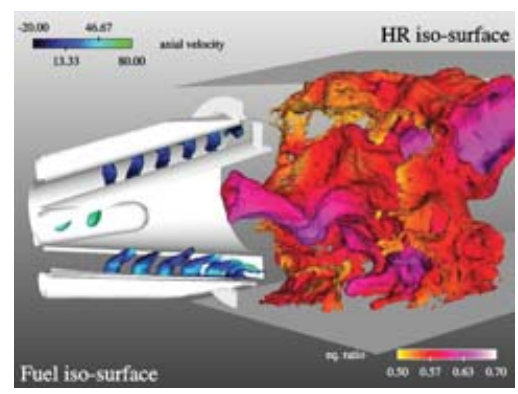

$315^{\circ}$

FIGURE 26. Snapshots illustrating one cycle of the combustion instability (images are in clockwise direction starting bottom left).

heat release iso-surface coloured by equivalence ratio. At $225^{\circ}$, the fuel is accumulating close to the injections, is convected through the burner at $315^{\circ}$, reaches the chamber and burns at $45^{\circ}$ and finally starts to accumulate again at $135^{\circ}$. Note the flame flashing back inside the burner at $45^{\circ}$ and the fuel jets impacting on the opposite shell at $135^{\circ}$. A movie of a similar sequence with higher outlet reflection coefficient is available on the internet at http://www.cerfacs.fr/cfd/movies/ev7_inst.mov.

The equivalence ratio fluctuations observed in the instability mechanism are the cause of the higher NO emissions: because of the exponential dependence of NO on equivalence ratio, the dependence on variance of equivalence ratio (and therefore temperature) is also exponential. Therefore, the stronger equivalence ratio fluctuations for case 3 cause the stronger NO emissions.

Another important mechanism coupling velocity fluctuations and heat release fluctuations is often observed in burners: vortex-driven combustion instabilities (Poinsot et al. 1987), where the velocity fluctuations cause the formation of a vortex of unburnt gases which burn after a certain time delay. It is included in figure 21 as an alternative pathway (indicated by a star). This mechanism was not found in the present simulations.

\section{Conclusion}

This paper presents several important modelling aspects in LES of gas turbine combustion. Models for convective and radiative heat transfer were used as well as acoustic boundary conditions and combustion modelling.

The simulations of a realistic gas turbine burner confirm the importance of heat transfer modelling for $\mathrm{NO}$ emissions. Assuming adiabatic combustion does not affect 


$\begin{array}{ccrrrc} & \text { Species } k & v_{k 1} & \mu_{k 1}^{\prime} & \mu_{k 1}^{\prime \prime} & \beta_{1}=0 \\ & \mathrm{CH}_{4} & -1.0 & 0.9 & 0.0 & A_{f 1}=1.32 \times 10^{16} \text { (c.g.s.) } \\ \text { Equation (2.1a): } & \mathrm{O}_{2} & -1.5 & 1.1 & 0.0 & \\ & \mathrm{CO} & 1.0 & 0.0 & 0.0 & E_{1}=47780 \mathrm{cal} \mathrm{mol}^{-1} \\ & \mathrm{H}_{2} \mathrm{C} & 2.0 & 0.0 & 0.0 & \\ & & & & & \beta_{2}=0 \\ & \text { Species } k & v_{k 2} & \mu_{k 2}^{\prime} & \mu_{k 2}^{\prime \prime} & A_{f 2}=-1.8 \times 10^{10} \text { (c.g.s.) } \\ \text { Equation (2.1b): } & \mathrm{CO} & -1.0 & 1.0 & 0.0 & \\ & \mathrm{O}_{2} & -0.5 & 0.5 & 0.0 & E_{2}=16440 \mathrm{cal} \mathrm{mol}^{-1}\end{array}$

TABLE 5. Reaction coefficients for the methane chemistry of the 3S_CH4_PS1 scheme.

velocity fields but modifies $\mathrm{NO}_{X}$ levels by a factor of 5 . However, it was shown that the level of acoustic oscillation also controls the NO concentration considerably. When burner instabilities are triggered (by closing acoustically the outlet in the LES), the

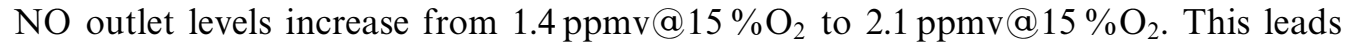
to the conclusion that meaningful simulations of gas turbine combustion require compressible formulations to capture unsteady features as well as acoustics.

LES were validated with extensive experimental data. Mixing and velocity predictions were good. The simulation including correct acoustics and heat transfer gave the best agreement with experiment in terms of flame position and shape. It will now be possible to study this burner for different operating conditions, as an alternative to experiments.

An extensive analysis of the combustion instability confirmed the usefulness of the balance equation for acoustic energy proposed by Martin et al. (2006). In addition, it was found that the dominant coupling process (at least during the limit cycle) is the interaction of acoustics with the fuel injections, thereby causing equivalence ratio fluctuations.

We would like to acknowledge CEA's Research and Technology Computing Centre (CCRT, Bruyères-le-Châtel, France) and the National Computer Centre of Higher Education (CINES, Montpellier, France) for providing some of the computational resources for this work, which was conducted in the framework of the FP5 EC-Project FuelChief.

\section{Appendix. The methane chemistry of the 3S_CH4_PS1 scheme}

The Arrhenius coefficients for the reduced mechanism used in this study are shown in table 5. They fit into the following approach based on the species reaction rates $\dot{\omega}_{k}$ due to combustion:

$$
\dot{\omega}_{k}=W_{k} \sum_{j=1}^{m} v_{k j} \mathscr{Q}_{j}
$$

where $v_{k j}$ is the difference of molar stoichiometric coefficients of consumed species $\left(v_{k j}^{\prime}\right)$ and produced species $\left(v_{k j}^{\prime \prime}\right)$

$$
v_{k j}=v_{k j}^{\prime \prime}-v_{k j}^{\prime},
$$


and $W_{k}$ is the molecular weight of species $k$. The progress rate $\left(\mathscr{Q}_{j}\right)$ of reaction $j$ is

$$
\mathscr{2}_{j}=K_{f j} \prod_{k=1}^{n}\left(\frac{\rho Y_{k}}{W_{k}}\right)^{\mu_{k j}^{\prime}}-K_{r j} \prod_{k=1}^{n}\left(\frac{\rho Y_{k}}{W_{k}}\right)^{\mu_{k j}^{\prime \prime}}
$$

where $K_{f j}$ and $K_{r j}$ are the forward and reverse rates of reaction $j$. The exponents $\mu_{k j}^{\prime}$ and $\mu_{k j}^{\prime \prime}$ are normally identical to $v_{k j}^{\prime}$ and $v_{k j}^{\prime \prime}$.

The forward rate constants are modelled by the Arrhenius law:

$$
K_{f j}=A_{f j} T^{\beta_{j}} \exp \left(-\frac{E_{j}}{R T}\right)
$$

with $A_{f j}$ the pre-exponential constant, $\beta_{j}$ the temperature exponent and $E_{j}$ the activation energy. The reverse rate constants are computed through equilibrium constants:

$$
K_{r j}=\frac{K_{f j}}{\left(p_{a} / R T\right)^{\sum_{k=1}^{n} v_{k j}} \exp \left(\Delta S_{j}^{0} / R-\Delta H_{j}^{0} / R T\right)}
$$

where $p_{a}=100 \mathrm{kPa}$. The $\Delta$ symbols refer to changes occurring when passing from reactants to products in the $j$ th reaction: $\Delta S_{j}^{0}$ and $\Delta H_{j}^{0}$ are respectively entropy and enthalpy changes for reaction $j$. These quantities are obtained from tables.

\section{REFERENCES}

Angelberger, C., Veynante, D. \& Egolfopoulos, F. 2000 Large Eddy Simulations of chemical and acoustic forcing of a premixed dump combustor. Flow, Turb. Combust. 65 (2), 205-222.

Barlow, R., Karpetis, A., Frank, J. \& Chen, J.-Y. 2001 Scalar profiles and no formation in laminar opposed-flow partially premixed methane/air flames. Combust. Flame 127, 2102-2118.

Baum, M., Thevenin, D. \& Poinsot, T. 1994 Accurate boundary conditions for multispecies reacting flows. J. Comput. Phys. 116, 247-261.

BÉdat, B., Egolfopoulos, F. \& Poinsot, T. 1999 Direct numerical simulation of heat release and NOx formation in turbulent nonpremixed flames. Combust. Flame 119 (1), 69-83.

Branley, N. \& Jones, W. P. 2001 Large Eddy Simulation of a turbulent non-premixed flame. Combust. Flame 127, 1914-1934.

Butler, T. \& O'Rourke, P. 1977 A numerical method for two-dimensional unsteady reacting flows. In 16th Symp. (Intl) on Combustion, pp. 1503-1515.

Савот, W. \& Moin, P. 2000 Approximate wall boundary conditions in the large-eddy simulation of high reynolds number flow. Flow Turb. Combust. 63, 269-291.

Chakravarthy, V. K. \& Menon, S. 2000 Large-Eddy Simulation of turbulent premixed flames in the flamelet regime. Combust. Sci. Technol. 7, 1-48.

Colin, O., Ducros, F., Veynante, D. \& Poinsot, T. 2000 A thickened flame model for large eddy simulations of turbulent premixed combustion. Phys. Fluids 12, 1843-1863.

Colin, O. \& Rudgyard, M. 2000 Development of high-order Taylor-Galerkin schemes for unsteady calculations. J. Comput. Phys. 162 (2), 338-371.

DAVID, J. 2004 Modélisation des transferts radiatifs en combustion par methode aux ordonnées discretes sur des maillages non structurés tridimensionnels. PhD thesis, INP Toulouse.

DEARDORFF, J. 1970 A numerical study of three-dimensional turbulent channel flow at large Reynolds numbers. J. Fluid Mech. 41, 453-480.

Doebbeling, K., Eroglu, A., Joos, F. \& Hellat, J. 1999 Novel technologies for natural gas combustion in turbine systems. In Eurogas 99. Ruhr University Bachum.

Duchamp de Lageneste, L. \& Pitsch, H. 2000 A level-set approach to large eddy simulation of premixed turbulent combustion. In CTR Annual Research Briefs.

Glarborg, P., Miller, J. \& Kee, R. 1986 Kinetic modeling and sensitivity analysis of nitrogen oxide formation in well-stirred reactors. Combust. Flame 65, 177-202. 
Gore, J., Lim, J., Takeno, T. \& Zhu, X. 1999 A study of the effects of thermal radiation on the structure of methane/air counter-flow diffusion flames using detailed chemical kinetics. In Book of Abstracts of the 5th ASME/JSME Joint Thermal Engineering Conference, p. 50 .

GrosshandLeR, W. 1993 RADCAL: A narrow-band model for radiation calculations in a combustion environment. Tech. Rep. 1402. NIST.

GrötzвACH, G. 1987 Direct numerical and larger eddy simulation of turbulent channel flows. In Encyclopedia of Fluid Mechanics, pp. 1337-1391. West Orange.

JANICKA, J. \& SADIKI, A. 2005 Large eddy simulation of turbulent combustion systems. In 30th Symp. (Intl) on Combustion, pp. 537-547.

Ju, Y., Masuya, G. \& Ronney, P. 1998 Effects of radiative emission and absorption on the propagation and extinction of premixed gas flames. In 27th Symp. (Intl) on Combustion, pp. 2619-2626.

Kee, R., Grcar, J., Smooke, M., Miller, J. \& Meeks, E. 1998 Premix: a fortran program for modeling steady laminar one-dimensional premixed flames. Tech. Rep. Sandia National Laboratories.

Keller, J. 1995 Thermoacoustic oscillations in combustion chambers of gas turbines. AIAA J. 33 (12), 2280-2287.

Launder, B. \& Spalding, D. 1974 The numerical computation of turbulent flows. Computer Meth. Appl. Mech. Engng 3, 269-289.

Lefebvre, A. 1998 Gas Turbine Combustion. Taylor \& Francis.

Lieuwen, T. C. 2001 A mechanism of combustion instability in lean premixed gas turbine combustors. J. Engng Gas Turbines Power 123, 182-189.

Martin, C. 2004 EPORCK user guide V1.8. Tech. Rep. TR/CFD/04/84. CERFACS.

Martin, C., Benoit, L., Nicoud, F. \& Poinsot, T. 2004 Analysis of acoustic energy and modes in a turbulent swirled combustor. In Proc. Summer Program, pp. 377-394. Center for Turbulence Research, NASA AMES/Stanford University.

Martin, C., Benoit, L., Sommerer, Y., Nicoud, F. \& Poinsot, T. 2006 LES and acoustic analysis of combustion instability in a staged turbulent swirled combustor. AIAA J. 44, 741-750.

Meneveau, C. \& Poinsot, T. 1991 Stretching and quenching of flamelets in premixed turbulent combustion. Combust. Flame 86, 311-332.

Miller, J. \& Bowman, C. 1989 Mechanism and modeling of nitrogen chemistry in combustion. Prog. Energy Combust. Sci. 15, 287-338.

Moin, P., Pierce, C. \& Pitsch, H. 2000 Large Eddy Simulation of turbulent, nonpremixed combustion. In Advances in Turbulence VIII, pp. 385-392. CIMNE, Barcelona.

Moureau, V., Lartigue, G., Sommerer, Y., Angelberger, C., Colin, O. \& Poinsot, T. 2005 Numerical methods for unsteady compressible multi-component reacting flows on fixed and moving grids. J. Comput. Phys. 202 (2), 710-736.

Nicol, D., Malte, P., Lai, J., Marinov, N. \& Pratt, D. 1992 NOx sensitivities for gas turbine engines operated on lean-premixed combustion and conventional diffusion flames. In $A S M E$ Intl Gas Turbine and Aeroengine Congress and Exposition.

Peters, N. 2000 Turbulent Combustion. Cambridge University Press.

Piomelli, U. \& Balaras, E. 2002 Wall-layer models for large-eddy simulations. Annu. Rev. Fluid Mech. 34, 349-374.

Poinsot, T. \& Lele, S. 1992 Boundary conditions for direct simulations of compressible viscous flows. J. Comput. Phys. 101 (1), 104-129.

Poinsot, T., Trouvé, A., Veynante, D., Candel, S. \& Esposito, E. 1987 Vortex driven acoustically coupled combustion instabilities. J. Fluid Mech. 177, 265-292.

Poinsot, T. \& Veynante, D. 2005 Theoretical and Numerical Combustion, 2nd Edn. R.T. Edwards.

Poinsot, T., Veynante, D. \& Candel, S. 1991 Quenching processes and premixed turbulent combustion diagrams. J. Fluid Mech. 228, 561-605.

RAYLEIGH, LORD 1878 The explanation of certain acoustical phenomena. Nature, July 18 pp. 319-321.

Sagaut, P. 2000 Large Eddy Simulation for Incompressible Flows. Springer.

Schumann, U. 1975 Subgrid scale model for finite difference simulations of turbulent flows in plane channels and annuli. J. Comput. Phys. 18, 376-404. 
Selle, L., Lartigue, G., Poinsot, T., Koch, R., Schildmacher, K.-U., Krebs, W., Prade, B., Kaufmann, P. \& Veynante, D. 2004a Compressible Large-Eddy Simulation of turbulent combustion in complex geometry on unstructured meshes. Combust. Flame 137 (4), 489-505.

Selle, L., Nicoud, F. \& Poinsot, T. $2004 b$ The actual impedance of non-reflecting boundary conditions: implications for the computation of resonators. AIAA J. 42 (5), 958-964.

Smagorinsky, J., Manabe, S. \& Holloway, S. 1963 General circulation experiments with the primitive equations. Mon. Weather Rev 91 (3), 99-164.

Smith, G. P., Golden, D. M., Frenklach, M., Moriarty, N. W., Eiteneer, B., Goldenberg, M., Bowman, C. T., Hanson, R. K., Song, S., Gardiner, W. C., Lissianski, V. V. \& Qin, Z. 1999 Gri-Mech Website. In http://www.me.berkeley.edu/gri-mech.

TAine, J. \& Petit, J.-P. 1995 Transferts Thermiques. Dunod.

WeI, T. \& Willmarth, W. 1989 Reynolds-number effects on the structure of a turbulent channel flow. J. Fluid Mech. 204, 57-95. 